\title{
Lineamiento técnico de atención para procedimientos con sedación durante la etapa de confinamiento y posterior declarados por la pandemia por COVID-19
}

Asociación Latinoamericana de Odontopediatría. Equipo Interdisciplinario COVID-19.

\section{Justificación}

Desde la Organización Mundial de la salud se realizó una alocución mundial por parte del Director General, Dr. Tedros Adhanom, el 11 de marzo de 2020, en la cual declaraba la situación de pandemia por el coronavirus. Debido a la rápida propagación de la enfermedad en todos los países en el mundo, se encuentran mas de 6.500.000 de personas contagiadas y casi 400.000 mil muertos en todo el mundo. Para el mes de junio, el epicentro de la pandemia se encuentra en países como Estados Unidos y Latinoamérica, donde Brasil representa el país con mayor numero de casos en la región. ${ }^{1,2}$ Esta situación representa un motivo de preocupación no solo para la organización mundial de la salud sino también para todos los gobiernos de la región debido al efecto devastador que puede tener la pandemia en Latinoamérica debido a la limitación evidente en los recursos de salud, lo que puede colapsar los sistemas de salud y aumentar significativamente el número de victimas fatales por el virus. ${ }^{2}$

En respuesta al número creciente de casos de COVID-19 durante la pandemia de 2020, muchos gobiernos en Latinoamérica han declarado el estado de emergencia, lo que conllevó como principal medida la imposición de una cuarentena y restricciones en la circulación normal de los ciudadanos.

Con estas medidas se pretende aislar a los habitantes, para evitar el contacto estrecho entre las comunidades con el fin de disminuir la velocidad del contagio y salvaguardar la salud de las personas mas vulnerables. Esta limitación en la actividad normal de los ciudadanos implica la suspensión de las actividades escolares, universitarias, suspensión de eventos masivos y espectáculos, el cierre de actividades comerciales, la limitación al transporte publico, entre otras medidas.

Las restricciones también incluyen la reducción en la prestación de los servicios de salud ambulatorios o electivos, los tratamientos que se realizan en los consultorios de odontología, y sólo se permiten realizar tratamientos de carácter urgente o inaplazable (siempre que la demora de los tratamientos pueda 
suponer un perjuicio para la salud del paciente). En este contexto los gobiernos hacen un llamado para no exponer la salud de los pacientes, ni la del personal de salud que trabaja en los consultorios, así como para la actuación responsable respetando las medidas establecidas por las secretarías de salud y por las autoridades gubernamentales de cada país. 3,4

No obstante, es necesario prepararse paralelamente para el periodo posterior a la crisis creada por la pandemia. En este momento se están desarrollando los protocolos específicos oficiales para implementar de manera clara cómo se debe iniciar la atención en odontología y odontopediatría en la práctica diaria, posterior al confinamiento, para trabajar con las mejores garantías de protección para los pacientes y para el equipo de salud. ${ }^{5,6}$

Basado en este contexto se redactó este documento, el cual presenta un plan de atención con una serie de pautas que pueden ser de utilidad al momento de atender los pacientes en la consulta de odontología. Debido a la gran incertidumbre que representa el alto porcentaje de pacientes contagiados asintomáticos en Latinoamérica, se deben tener pautas muy claras que proporcionen estrategias efectivas de cuidado con el fin de evitar el contagio del coronavirus en las áreas clínicas asistenciales donde se atienden pacientes. Es importante resaltar que este documento es dinámico y se debe actualizar periódicamente, conforme se publique más información científica relevante.

\section{Introducción}

Es indispensable desarrollar e implementar el lineamiento técnico para la atención segura de pacientes durante el confinamiento y posterior a él, por la pandemia del COVID-19 mientras este presente el virus en la comunidad.

El objetivo de este lineamiento técnico es asegurar la protección de los pacientes que requieren una atención urgente $o$ prioritaria en odontología bajo sedación; así como el cuidado del personal de salud involucrado en dicha atención, para evitar el posible contagio o transmisión de la enfermedad.

Los objetivos de este lineamiento técnico son:

1. Implementar una guía clara para realizar la programación de un paciente en odontología y odontopediatría que requiere sedación durante la pandemia por el COVID-19.

2. Describir los pasos para asegurar la atención de los pacientes en el consultorio odontológico que permita garantizar la calidad de la atención y disminuir el riesgo de transmisión o contagio del coronavirus entre pacientes y personal médico/ odontológico.

3. Desarrollar las actualizaciones periódicas que requiera este documento de acuerdo con los cambios recomendados por la Organización Mundial de la Salud y las agremiaciones médicas y odontológicas para prevenir y tratar efectivamente la infección por coronavirus.

Práctica de la sedación en ambientes de odontología y odontopediatría durante la pandemia por el COVID-19

\section{Etapa de confinamiento}

Durante la etapa de confinamiento, se realizarán solo sedaciones de pacientes 
para tratamiento odontológicos que presenten emergencia o urgencia odontológica, se diferirá todo tratamiento electivo para después del periodo de confinamiento señalado por las autoridades gubernamentales locales.

Los procedimientos odontológicos están categorizados como procedimientos de alto riesgo de contagio para coronavirus debido a que involucra fluidos como la saliva que, en pacientes contagiados, presenta una carga viral muy alta. La transmisión aérea puede ocurrir durante estos procedimientos porque generan aerosoles en la boca y en la vía aérea del paciente, los cuales pueden tener alta concentración del virus y ocasionar contagio. ${ }^{5,7}$ El coronavirus (SARS-CoV-2) puede transmitirse por contacto directo con superficies contaminadas o por vía de gotículas dispersadas a menos de 2 metros de distancia por una persona infectada. ${ }^{8}$

\section{Después de la etapa de confinamiento}

El inicio en la programación de los pacientes para la consulta de odontología en la etapa posterior a la cuarentena estará regulada por las autoridades de salud de acuerdo con las directrices de los gobiernos de cada país.

La programación de los pacientes en los consultorios de odontología se regirá por las nuevas normas de seguridad en la atención durante la pandemia del COVID-19, lo que implica una programación más espaciada que garantice los procesos de desinfección, esterilización y restricción para el ingreso de varias personas al área del consultorio. Estas medidas se deben aplicar con el fin de disminuir el riesgo de contagio y de conservar al máximo las medidas de prevención y el aislamiento social que deben seguir cumpliendo los pacientes, los familiares (en el caso de Odontopediatría), el personal médico, odontológico, auxiliares y el personal administrativo que se encuentra involucrado en la atención de los pacientes en la consulta. ${ }^{3}$

\section{Generalidades de la pandemia del COVID-19}

\section{Definiciones}

El COVID-19 es una enfermedad contagiosa transmitida por un nuevo coronavirus llamado SARS-CoV-2. Hace parte del grupo de enfermedades conocidas como zoonosis donde el virus inicial pasa de los animales (descrito inicialmente en murciélago y pangolín) y posteriormente logra contagiar a los seres humanos.

El coronavirus pertenece a una familia de virus que causan infección respiratoria aguda, de los cuales hay 4 tipos antiguos que producen infección respiratoria leve y hay 2 tipos nuevos más agresivos (que causan el SARS y el MERS). El coronavirus es un betacoronavirus específico que produce el COVID-19 y se ha denominado SARS-CoV-2. ${ }^{9}, 10$

La proteína Spike que recubre la capa bifosfolipida del virus (le da un aspecto de corona) se adhiere al receptor de angiotensina en la membrana del neumocito, lo que causa su destrucción y activa una cascada masiva de citoquinas que causan daño inflamatorio severo inicialmente en el pulmón pero luego afecta todos los órganos. ${ }^{11-12}$ 
Se diagnostica con prueba de RT-PCR en secreciones respiratorios (nariz, orofaringe o bronquios) en fase aguda, en los primeros 5 días, y luego de 6 - 14 días de iniciados los síntomas los pacientes desarrollan anticuerpos tipo IG M e IgG en suero. El periodo de incubación promedio es de 5-6 días, pero hay evidencia científica de que ese periodo en algunos casos se ha prolongado hasta los 14 días. Hay que tener en cuenta que muchos pacientes son asintomáticos, o presentan sintomatología muy leve, esto es especialmenteimportante en niños desde 1 a 17 años. Los exámenes diagnósticos tienen una sensibilidad y especificidad diferente de acuerdo con el momento del contagio. En la figura 1 se muestran los periodos de detección del virus y las pruebas que se deben realizar según la evolución de los síntomas.

El $80 \%$ de los pacientes manifiestan tos seca, fiebre (>38 grados), odinofagia, náuseas y vómito o diarrea (sólo el 20\% de los casos). La mayoría de los pacientes se mejoran con tratamiento sintomático en casa, pero el $20 \%$ pueden requerir hospitalización debido a la progresión de los síntomas los cuales se manifiestan con fiebre mayor de $38^{\circ}$ por mas de 2 días, disnea o dificultad respiratoria y malestar general, con saturación de oxígeno $<90 \%$ al ambiente. Aproximadamente el 5\% de los pacientes desarrollan neumonía severa con progresión a SDRA (síndrome de dificultad respiratoria del adulto), algunos además progresan a falla renal $\mathrm{y}$ requieren manejo integral en unidad de cuidados intensivos (UCI). ${ }^{13}$

Actualmente el tratamiento es solo sintomático y de soporte vital según la severidad del caso. La tasa de fatalidad por coronavirus se ubica entre el 2 y el $6 \%$, pero varía de acuerdo con el grupo de edad. Es más baja en la población pediátrica menor de 20 años (mortalidad $<1 \%$ ), pero es mayor en los pacientes mayores de

\section{Días post infección}

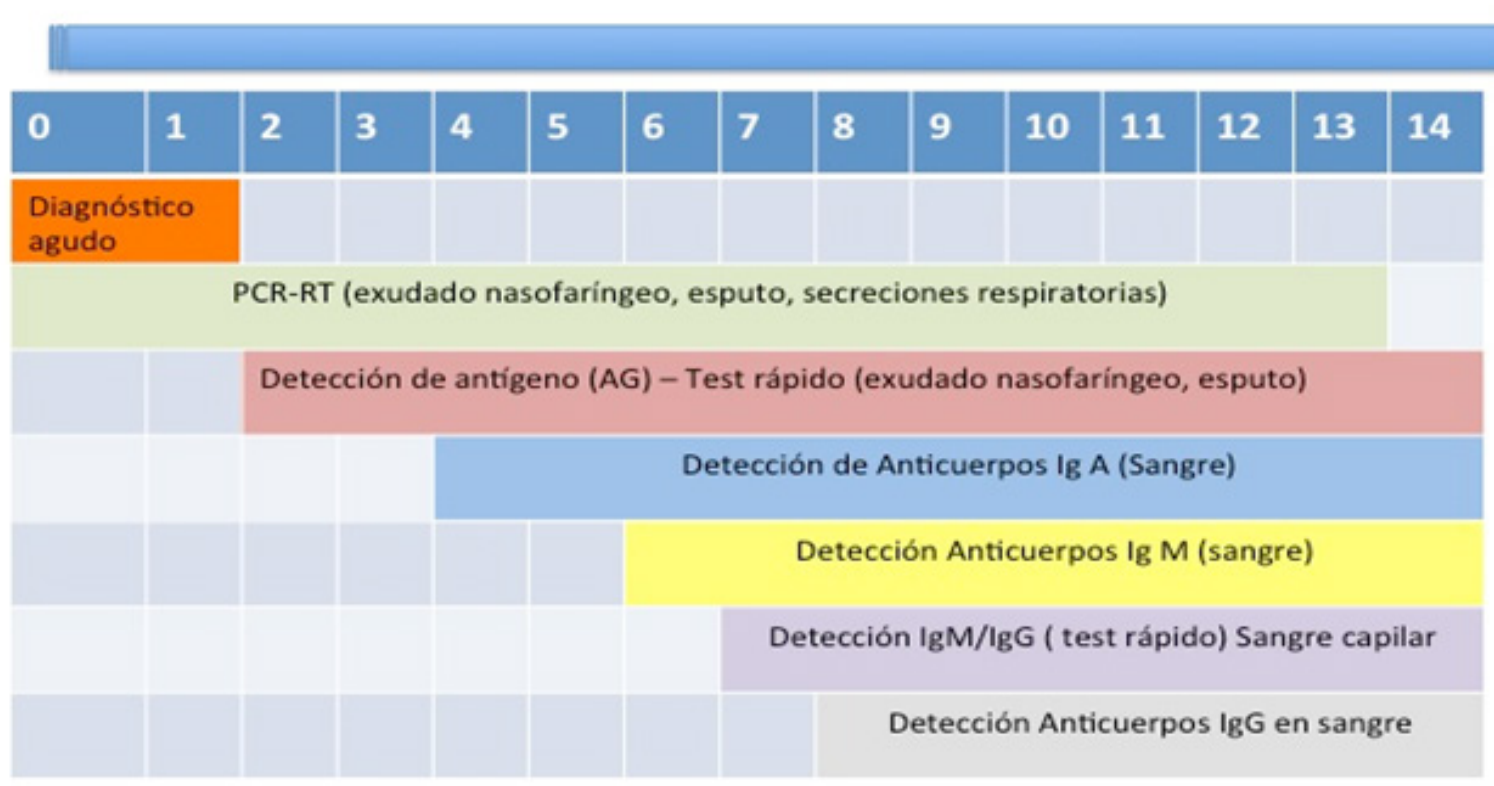

Figura 1. Tipo de pruebas para diagnóstico de COVID-19 
60 años, con cifras que pueden ascender hasta el $15 \%$ de mortalidad. Existen factores de riesgo como las enfermedades crónicas, las cuales también aumentan la severidad de la enfermedad y el porcentaje de muerte. Los factores de riesgo identificados hasta ahora son: hipertensión arterial (HTA), diabetes mellitus (DM), enfermedad pulmonar obstructiva crónica (EPOC), cáncer, enfermedades cardiacas, enfermedades autoinmunes, inmunosupresión (farmacológica o por enfermedad), tabaquismo, obesidad $y$ desnutrición. ${ }^{14}$

Existe otro grupo de riesgo y se trata del personal sanitario, el cual se ha reportado que tiene una alta probabilidad de contagio. Los últimos datos disponibles de China muestran que se han visto afectados 1.716 trabajadores de la salud $(3,8 \%$ de todos los infectados en China); y los datos disponibles en España e Italia reportan un porcentaje de contagio cercano al 18,5\% (más de 31.000 casos), lo que muestra que el personal de salud es un grupo de muy alto riesgo debido a que se exponen a cargas virales mucho más altas y de varios pacientes a la vez. ${ }^{15}$

El coronavirus es 10 veces más contagioso que el virus de la influenza, de ahí el exponencial número de contagios que ha mostrado alrededor de todo el mundo con un índice de contagio por persona (R0) de 2-3.

\section{Mecanismos de contagio}

El contagio se da por una de las siguientes 3 rutas:

1- Transmisión directa: porque al expectorar, toser, estornudar o hablar el paciente infectado lanza gotas o microgotas hasta 2 metros de distancia que son inhaladas por personas sanas.
2- Transmisión de contacto con superficies contaminadas: por gotas ( $>5$ micras ) que se quedan adheridas a las superficies, las cuales son tocadas por otras personas sanas que inadvertidamente llevan las manos a la cara y producen la autoinoculación en ojos, nariz o boca. Puede ocurrir también que haya un contacto cercano con fluidos de las personas infectadas (incluida la saliva) las cuales también transmiten la infección.

3- Transmision de aerosoles por procedimientos médicos $u$ odontológicos: Este mecanismo es el responsable de los contagios en el personal de salud que está expuesto a procedimientos que generan aerosoles y liberan partículas del virus en el medio ambiente, que luego son inhalados por el personal cercano al paciente y asi contraen la enfermedad. . $^{7}$

De acuerdo con la transmisión se debe describir el tipo de aislamiento:

Aislamiento respiratorio: Se aplica cuando se prevé la presencia de gotas de origen respiratorio con bajo rango de difusión (hasta 1 metro).

Aislamiento por gotas: Se refiere a las medidas para controlar las infecciones por virus respiratorios y otros agentes transmitidos por gotas (> 5 micras) impulsadas a corta distancia a través del aire y que pueden ingresar a través de los ojos, la mucosa nasal, la boca o la piel no intacta de la persona que está en contacto con el paciente.

Aislamiento por contacto: Se refiere a las medidas para controlar: el contacto directo, cuando se produce traspaso de sangre o fluidos corporales desde un paciente hacia otro individuo, el contacto puede hacerse en piel, mucosas o lesiones, o por inóculos directos al torrente sanguíneo; y 
el contacto indirecto, cuando el huésped susceptible entra en contacto con el microorganismo infectante a través de un intermediario inanimado (ropas, fómites, superficies de la habitación) o animado (personal de salud, otro paciente) que estuvo inicialmente en contacto con ese microorganismo. ${ }^{16}$

\section{Médidas de prevención}

El coronavirus tiene en su capa externa un recubrimiento lipídico que protege la estructura viral. Esta capa es sensible y fácilmente destruible con detergentes, jabones, alcohol (más del 70\%), soluciones de hipoclorito de sodio mayor al $0,2 \%$, solución de glutaraldehido al $2 \%$ o amonio cuaternario al $0,2 \%$.

Medidas generales para todos:

- En áreas de circulación para todo el personal que labora e ingresa al consultorio, debe realizar un adecuado lavado de manos por al menos 20 segundos.

- Evitar tocarse los ojos, la nariz o la boca

- Estornudar o toser en el antebrazo o en un pañuelo desechable el cual se debe inmediatamente botar en una cesta con tapa.

- Evitar saludos de mano, beso o abrazo y mantener el distanciamiento social al menos de 2 metros de distancia.

- Evitar el contacto con personas enfermas o con síntomas respiratorios. En este caso el paciente con síntomas debe utilizar tapabocas o mascarilla todo el tiempo y mantener el distanciamiento social de al menos 2 metros.
- Mantener el aislamiento de personas mayores de 65 años o pacientes con factores de riesgo. Este tipo de pacientes sólo deben asistir a la consulta de odontología en casos de urgencia odontológica inaplazable y para procedimientos prioritarios donde no se expongan al contacto social.

- Los pacientes pediátricos también deben permanecer en aislamiento preventivo debido a que es un grupo poblacional que se contagia fácilmente y son portadores asintomáticos del virus. La atención odontológica en este grupo de edad debe priorizarse y seleccionar muy bien la causa y la urgencia en la atención. ${ }^{17,18}$

\section{Clasificación de la atención en odontología y odontopediatría}

Emergencia Odontológica: patología de origen odontológico con potencial riesgo de comprometer la vida del paciente por lo que requiere tratamiento inmediato. Ejemplo de emergencias odontológicas son: hemorragia incontrolada, celulitis facial con edema de la cavidad oral que compromete la vía aérea o los tejidos blandos del cuello y trauma dentofacial que puede comprometer la vía aérea. Estos pacientes requieren manejo intrahospitalario. ${ }^{3}$

Urgencia Odontológica: patología odontológica que requiere manejo inmediato para aliviar el dolor severo o controlar una infección aguda como pulpitis irreversible severa, pericoronitis, absceso dentoalveolar localizado, fractura dental con dolor, alveolitis, trauma dental con avulsión o luxación, hemorragia y toma de biopsias o preparación odontológica previa a un procedimiento quirúrgico. 
Estos tratamientos se pueden realizar en el consultorio odontológico bajo sedación, cuando hay una indicación determinada por el odontólogo o por el paciente. ${ }^{3}$

Los tratamientos odontológicos en pacientes que requieren sedación deben ser procedimientos radicales $y$ definitivos que resuelvan el problema odontológico del paciente y que a su vez reduzcan la probabilidad de nuevas intervenciones o de consultas posteriores al procedimiento para disminuir el riesgo de exposición.

Protocolo para la atención de urgencias odontológicas en consultorio bajo sedación

Medidas que se deben cumplir antes de la atención odontológica para el odontólogo, el médico anestesiólogo y las auxiliares.
Comprobación del estado de salud del personal de la clínica

Parece evidente que es imprescindible asegurarse de que el estado de salud de todo el personal de la clínica permite su reincorporación a su puesto de trabajo con las garantías adecuadas para ello. Por lo tanto se debe llevar un registro del personal de salud que trabaja en los consultorios de odontología, los cuales debe cumplir con los requisitos que aparecen en la Tabla 1.

La reincorporación del personal de salud después de la etapa de confinamiento tiene tres pasos en la lista de verificación:

1. Comprobación del estado de salud del personal de la clínica o consultorio.

2. Socialización y educación en la implementación de los protocolos de bioseguridad.

3. Supervisión y puesta en marcha de los protocolos.

\section{Tabla 1.}

\begin{tabular}{|l|c|c|c|}
\hline & ADA & CDC & FDI \\
\hline $\begin{array}{l}\text { Esquema de vacunación completo Énfasis en dosis de influenza el año } \\
\text { anterior y hepatitis B. }\end{array}$ & SI & SI & SI \\
\hline $\begin{array}{l}\text { No se debe acudir al consultorio si se tiene algún signo o síntoma de } \\
\text { cuadro gripal en las últimas 2 semanas. }\end{array}$ & SI & SI & SI \\
\hline $\begin{array}{l}\text { Personal de la salud, mayor de } 60 \text { años o con factores de riesgo, no } \\
\text { deben atender la urgencia odontológica }\end{array}$ & SI & SI & SI \\
\hline $\begin{array}{l}\text { El equipo debe realizarse automonitoreo para detectar cualquier signo } \\
\text { de alerta de infección respiratoria, incluida toma de temperatura 2 ve- } \\
\text { ces al día (normal }<37,5)\end{array}$ & SI & SI & SI \\
\hline $\begin{array}{l}\text { Los profesionales y auxiliares que recientemente contrajeron y se re- } \\
\text { cuperaron de una infección por COVID-19 deben ser preferiblemente } \\
\text { quienes brinden la atención odontológica. Una vez sea confirmada la } \\
\text { curación de la enfermedad con dos pruebas de PCR negativas en 24 } \\
\text { horas. }\end{array}$ & SI & NO & NO \\
\hline
\end{tabular}

ADA: Asociación Dental Americana. CDC: Centro de control de Enfermedades. FDI: Federación Dental Internacional. 
Paso 1: Planificación de la atención odontopediátrica bajo sedación

Antes de programar un paciente para atención de urgencias odontológicas durante el periodo de confinamiento se debe realizar una capacitación a todo el personal vía virtual por teleconferencia (desarrollar un acta de dicha teleconferencia). Y una vez se confirme la atención y la presencia del personal que va a atender la urgencia, se debe hacer un simulacro sobre las diferentes actividades que debe desarrollar el personal de salud, hacer énfasis en la colocación y el retiro de los elementos de protección personal (EPP) y su correcto desecho (simulacro para el odontólogo, anestesiólogo y auxiliares). Se debe realizar un acta por escrito firmada con los asistentes y se guardará en carpeta rotulada que permita fácil identificación d elos pasos seguidos. ${ }^{16,19}$

1. El odontólogo programa la urgencia odontológica del paciente. Confirma disponibilidad con anestesiólogo y auxiliares de enfermería y odontología.

2. Se confirma la indicación de la sedación, la cual puede ser solicitada por el odontólogo o por el paciente.

3. Se realiza una historia clínica rápida para identificar riesgos $\mathrm{y}$ contraindicaciones de la sedación.

4. Consulta anestésica presedación vía telefónica con el paciente. ${ }^{20}$

Los pacientes que requieran atención presencial en el consultorio de odontología pueden requerir sedación endovenosa para mejorar las condiciones y asegurar una adecuada atención odontológica. ${ }^{21}$ Está contraindicado en el consultorio dental la realización de sedación inhalatoria con
Óxido Nitroso en el marco de la pandemia COVID-19 por aumentar el riesgo de contagio por aerosoles. ${ }^{22}$ Los pacientes que, por el tipo de tratamiento a realizar o sus condiciones médicas, incluyendo diagnóstico de COVID-19, requieran anestesia general deben ser remitidos para tratamiento intrahospitalario y tratados conjuntamente con el equipo médico.

La sedación de los niños en un consultorio de odontología implica necesariamente la participación de un equipo multidisciplinario de acuerdo con la profundidad de la sedación, que incluye el odontólogo, el auxiliar de odontología, el anestesiólogo y un auxiliar de enfermería. Aunque hacer intervenciones farmacológicas por fuera del quirófano es un gran reto, lograr una atención integral de excelente calidad durante los tratamientos odontológicos en los pacientes, resulta muy gratificante para odontopediatras, cirujanos maxilofaciales y anestesiólogos. ${ }^{21,23,24}$

Las indicaciones y contraindicaciones para administrar sedación en odontopediatría, según Rubiano et al. ${ }^{21}$ se muestran en la Tabla 2.

El equipo necesario para administrar la sedación incluye la presencia de personal, en este caso un Médico Anestesiólogo graduado, con competencias en el manejo de la vía aérea y certificado vigente de cursos de reanimación: PALS (Reanimación Pediátrica Avanzada) y ACLS ( Reanimación Cardiovascular en el Adulto).

Auxiliar de enfermería graduada y con experiencia en salas de cirugía o cuidado intensivo y con certificado vigente en Curso Básico de Reanimación (BLS). 
Tabla 2. Indicaciones y contraindicaciones para la sedación en odontopediatría. ${ }^{21}$

\begin{tabular}{|c|c|}
\hline \multicolumn{2}{|c|}{ Indicaciones de la sedación para procedimientos odontológicos en los niños } \\
\hline $\begin{array}{l}\text { Indicaciones de la sedación para procedimientos } \\
\text { odontológicos en los niños menores de } 12 \text { años }\end{array}$ & $\begin{array}{l}\text { Indicaciones para sedación en procedimientos } \\
\text { odontológicos en pacientes mayores de } 12 \text { años }\end{array}$ \\
\hline $\begin{array}{l}\text { Niños con poco o nulo potencial de coopera- } \\
\text { ción. }\end{array}$ & $\begin{array}{l}\text { Pacientes ansiosos o que no pueden cooperar } \\
\text { durante la valoración odontológica. }\end{array}$ \\
\hline $\begin{array}{l}\text { Niños con odontofobia, miedo o ansiedad in- } \\
\text { controlable. }\end{array}$ & Pacientes con odontofobia. \\
\hline Niños con reflejo nauseoso aumentado. & $\begin{array}{l}\text { Pacientes con alto reflejo nauseóso o que no } \\
\text { toleren mantener la boca abierta por largo } \\
\text { tiempo. }\end{array}$ \\
\hline $\begin{array}{l}\text { Niños con retraso psicomotor leve de cualquier } \\
\text { tipo. }\end{array}$ & \multirow{2}{*}{$\begin{array}{l}\text { Pacientes con enfermedad cardiovascular con } \\
\text { hipertensión arterial o enfermedad coronaria } \\
\text { en quienes es ideal tener monitorización conti- } \\
\text { nua de su función cardiovascular y disminuir } \\
\text { la ansiedad para evitar incrementos no con- } \\
\text { trolados de la tensión arterial, sobre todo si } \\
\text { requieren infiltración con anestésicos locales } \\
\text { con epinefrina. }\end{array}$} \\
\hline $\begin{array}{l}\text { Niños con condiciones psiquiátricas, cuando } \\
\text { no ha sido posible la adaptación por métodos } \\
\text { convencionales. }\end{array}$ & \\
\hline Procedimientos dolorosos. & \multirow{2}{*}{$\begin{array}{l}\text { Pacientes con problemas osteomusculares que } \\
\text { no les permite permanecer sentados en la silla } \\
\text { odontológica por largos periodos de tiempo }\end{array}$} \\
\hline Procedimientos complejos o de larga duración. & \\
\hline \multicolumn{2}{|c|}{ Contraindicaciones de la sedación para procedimientos odontológicos en los niños } \\
\hline \multicolumn{2}{|l|}{ Niños con clasificación ASA III o mayor. } \\
\hline \multicolumn{2}{|l|}{ Niños con clasificación de Mallampati 3 ó 4.} \\
\hline \multicolumn{2}{|c|}{ Niños con historia de prematurez y secuela de hipertensión pulmonar. } \\
\hline \multicolumn{2}{|l|}{ Menores de 2 años de edad. } \\
\hline \multicolumn{2}{|l|}{ Pacientes adolescentes en estado de embarazo. } \\
\hline \multicolumn{2}{|c|}{ Niños con cardiopatía congénita o con enfermedad pulmonar crónica. } \\
\hline \multicolumn{2}{|c|}{ Niños con alteración del estado de conciencia por cualquier patología. } \\
\hline \multicolumn{2}{|c|}{ Niños con alto riesgo de broncoaspiración o con reflujo gastroesofágico. } \\
\hline \multicolumn{2}{|l|}{ Niños con alteraciones de la vía aérea. } \\
\hline \multicolumn{2}{|c|}{$\begin{array}{l}\text { Niños con historia de apnea obstructiva del sueño, obesidad, anormalidades craneofaciales, des- } \\
\text { órdenes neuromusculares o síndrome de Down. }\end{array}$} \\
\hline $\begin{array}{l}\text { Niños con infección respiratoria alta activa, en } \\
\text { purulenta en las } 2 \text { últimas semanas, pues tiene } \\
\text { goespasmo y diez veces mayor de broncoespasr }\end{array}$ & $\begin{array}{l}\text { la cual están presentes fiebre, tos o rinorrea } \\
\text { una incidencia cinco veces mayor de larin- }\end{array}$ \\
\hline
\end{tabular}


Los equipos necesarios para administrar sedación se resumen en la Tabla 3. Cada profesional debe asegurarse de cumplir con las regulaciones y normativa vigente en su región. Es imprescindible la verificación del cumplimiento de todos los requisitos previo a la planificación de la cita del paciente.

Se debe dejar un registro físico o digital que contenga: la valoración presedación del paciente, el consentimiento informado exclusivo para la sedación firmado por el paciente o por su representante en caso de ser menor de edad; el registro de sedación con los medicamentos administrados, el seguimiento de los signos vitales y las condiciones de la sedación durante el procedimiento; $\mathrm{y}$ finalmente las complicaciones o eventos adversos que se hayan presentado, así como las recomendaciones y los cuidados que debe seguir el paciente después de la sedación. ${ }^{21,23,24}$

Toda actividad que requiera sedación debe contar con una red de apoyo para asistir en caso de emergencias o complicaciones con el paciente y que requiera trasladar el paciente a un centro hospitalario. Esta

Tabla 3. Equipos necesarios para administrar la sedación en odontopediatría. ${ }^{21}$

\begin{tabular}{|c|c|}
\hline \multicolumn{2}{|r|}{ Equipos necesarios para administrar la sedación en odontopediatría } \\
\hline $\begin{array}{l}\text { Requisitos para el } \\
\text { lugar }\end{array}$ & $\begin{array}{l}\text { Áreas que permitan el transito de camilla, oxígeno y monitor de signos } \\
\text { vitales. } \\
\text { Iluminación artificial o natural adecuada. } \\
\text { Mínimo una toma de energía exclusiva para cada equipo. } \\
\text { Una fuente de oxígeno cercana al paciente. } \\
\text { Tanque de oxígeno portátil de reserva para situaciones de emergencia. } \\
\text { Al menos un equipo de succión con extensiones hasta el paciente. }\end{array}$ \\
\hline Monitores & $\begin{array}{l}\text { Pulsoxímetria idealmente con onda pletismográfica } \\
\text { Presión arterial no invasiva } \\
\text { Cardioscopio de } 3 \text { ó } 5 \text { derivadas } \\
\text { Capnografía }\end{array}$ \\
\hline $\begin{array}{l}\text { Dispositivos de } \\
\text { vía aérea }\end{array}$ & $\begin{array}{l}\text { Cánulas o sondas de succión } \\
\text { Cánulas orofaríngeas } \\
\text { Máscara faciales tamaños pediátricos y adultos } \\
\text { Máscara laríngea de diferentes tamaños } \\
\text { Laringoscopio y hojas para intubar (rectas y curvas de todos los tamaños) } \\
\text { Guía o estilete para intubación } \\
\text { Dispositivo para administrar ventilación (Ambu o Ayree Rees) } \\
\text { Cánulas nasales pediátricas y adultos }\end{array}$ \\
\hline $\begin{array}{l}\text { Equipos para } \\
\text { reanimación } \\
\text { cardiopulmonar }\end{array}$ & $\begin{array}{l}\text { Catéteres para canalización intravenosa de todos los tamaños } \\
\text { Torniquete y apósito o cinta adhesiva para fijar el catéter } \\
\text { Equipos de venoclisis y bomba de infusión desechables } \\
\text { Soluciones intravenosas: Solución salina normal, Lactato de Ringer, } \\
\text { Dextrosa al 5\% } \\
\text { Medicamentos de emergencia: adrenalina, atropina, flumazenil, naloxona, } \\
\text { salbutamol inhalador, hidrocortisona, metilprednisolona, lidocaína, } \\
\text { amiodarona. }\end{array}$ \\
\hline
\end{tabular}


red de apoyo se debe verificar con los profesionales involucrados o de acuerdo con los convenios de la empresa de sedación.

Al finalizar la sedación, se realiza una desinfección de todos los equipos y monitores utilizados con el paciente utilizando una solución de alcohol al $70 \%$ o soluciones de amonio cuaternario diseñados para la desinfección de equipos médicos. ${ }^{25}$

Todo el personal que participa en la atención de odontología debe utilizar los mismos elementos de protección personal, ${ }^{25-28}$ los cuales se describen mas adelante.

\section{Protocolo para el consultorio odontológico y personal de salud: odontólogo, médico y auxiliares de enfermería/odontología}

1. Toma de temperatura 2 veces al dia (en la mañana y después del medio día) con termómetro digital, de lo cual se llevará registro escrito. No se puede permitir el ingreso o acompañamiento a las instalaciones, de personas que presenten síntomas de gripa o fiebre (temperatura igual o mayor a $37,5^{\circ} \mathrm{C}$ ). Se recomienda utilizar un termómetro de luz infraroja para evitar el contacto directo.

2. Llenar el formulario sobre test para COVID-19 diario por cada trabajador.

3. Lista de chequeo de los elementos de protección personal que debe utilizar el personal de salud que participa en la atención de la urgencia odontológica y asegurar el cumplimiento estricto de los lineamientos de bioseguridad.

Al llegar al consultorio, todo el personal de salud (odontológico y de sedación), personal administrativo, y de limpieza sin excepción debe:
1- Retirarse los sacos, las chaquetas y cambiarse la vestimenta para colocar el uniforme y zapatos cerrados que deben utilizar dentro del consultorio.

2- Guardar elementos como bolsos, maletines y celulares en áreas seguras y que no estén en las áreas donde se van a atender los pacientes. Así como se deben retirar accesorios como relojes, pulseras, anillos, collares y pendientes.

3- Lavarse manos y la cara antes de tocar cualquier superficie: con agua y jabón de clorhexidina o jabón con yodo (para reducir la flora transitoria de las manos y eliminar la flora residente).

4- Aplicar gel alcoholado en las manos y dejar secar por completo.

5- Utilizar calzado cerrado exclusivo para el consultorio o cubrir el calzado con cubre calzados desechables y utilizar un nuevo tapabocas convencional todo el tiempo que permanezca dentro del consultorio.

6- Se debe conservar en todo momento el aislamiento social, por lo que no se deben realizar saludo de mano, beso o abrazo a ningún compañero de trabajo.

7- Las citas programadas deben ser puntuales con un tiempo de espera adecuado entre pacientes para evitar que coincidan en la sala de espera, y se conserve la distancia de mínimo 2 metros entre las personas dentro del consultorio. Evitar en lo posible el uso de salas de espera colectivas, donde se pueden aglomerar un buen número de personas.

8- Limitar los puntos de ingreso al consultorio.

9- Retirar revistas, decoraciones y otros objetos con superficies que puedan 
contaminarse. Retirar cuadros, póster o diplomas de las zonas clínicas.

10- Se debe disponer de gel desinfectante para manos a base de alcohol al $70 \%$, pañuelos desechables y recipientes de basura a la entrada de las instalaciones con tapas que funcionen correctamente y permanezcan cerradas, salas de espera que garanticen el distanciamiento y los registros actualizados del paciente.

11- Mantener todas las áreas bien ventiladas y con buena luz natural. Si utiliza climatización, verificar que la temperatura esté entre 21 y $23^{\circ} \mathrm{C}$ y la humedad entre $30 \%$ y $50 \%$. Las áreas operatorias en las que se generarán aerosoles idealmente deben equipadas con una capacidad especial de manejo de aire y ventilación, es decir, presión negativa monitoreada en relación con el área circundante, 6-12 intercambios de aire y aire expulsado directamente al exterior o por hora con filtración HEPA. En el caso de no tener acceso a este sistema se recomienda realizar el procedimiento con ventanas abiertas (ventilación al exterior) y escasa circulación de personal (con puerta cerrada $)^{28}$

12- Evitar el uso de celular durante los procedimientos.

13- Se realizara limpieza y desinfección de superficies, incluyendo manijas de puertas, sillas, mesas y muebles del consultorio con alcohol al $70 \%$ o soluciones con hipoclorito al $0,2 \%$ o soluciones de amonio cuaternario de 5 ta generación, al inicio del día y entre la atención de un paciente y otro.

14- No ingresar al áerea operatoria sin respiradores N95 hasta 30 minutos después si se realizan 10 recambios,
138 minutos después si son 2 recambios, y hasta 3 horas después si el procedimiento generador de aerosoles se realiza en una habitación sin recambios

15- Planificar el procedimiento que se le vaya a realizar al paciente. Esta planificación permite organizar el material e instrumental estrictamente necesario, así como preparar el equipo de protección personal (EPP).

16- No tener a la vista material o instrumental que no se vaya a utilizar. Tenerlos bien guardados en cajoneras cerradas para evitar posible contaminación cruzada. ${ }^{28}$

\section{Técnica de lavado de manos}

- El lavado de manos con agua y jabón debe realizarse cuando las manos están visiblemente sucias, después de utilizar el baño, antes y después de comer, después de estornudar o toser, antes y después de ajustar o tocar el tapabocas.

- La higiene de manos con alcohol glicerinado se debe realizar siempre y cuando las manos están visiblemente limpias.

- El alcohol glicerinado a utilizar debe tener una concentración entre $60 \%$ y el $95 \%$.

- Se deben tener recordatorios de la técnica del lavado de manos en la zona en la cual se realiza la actividad lavado de manos. ${ }^{29,30}$

Capacitación a los trabajadores en aspectos básicos relacionados con la forma en que se transmite el COVID - 19 y las maneras de prevenirlo: 
- Disponer de información general relacionada con los lugares del consultorio en los que puede haber riesgo de exposición

- Factores de riesgo del hogar y la comunidad

- Factores de riesgo individuales

- $\quad$ Signos y síntomas

- Importancia del reporte de las condiciones de salud del personal

\section{Preparación para el paciente que recibirá tratamiento odontológico bajo sedación}

Todo paciente debe contestar la siguiente lista de chequeo como triage previo de infección por SARS-CoV-2 antes de cualquier programación, por teleconsulta (correo electrónico, teléfono $\mathrm{o}$ redes sociales) La ficha de despistaje para casos sospechosos de exposición a COVID-19 se incluye en el Anexo 1. Los datos mínimos a indagar son:

Datos básicos de identificación, antecedentes médico-quirúrgicos, procedimiento a realizar.

Riesgo para infección de COVID-19: explorar contacto con familiares $\mathrm{o}$ contacto social con personas positivas o sospechosas de infección por coronavirus en las últimas 2 semanas; presencia de síntomas respiratorios (tos seca, odinofagia, rinorrea, diarrea, dolor gastrointestinal, alteración del gusto o del olfato, fiebre, brote en la piel y malestar general en el paciente) en los últimos 14 días. ${ }^{16,19,26}$

Las preguntas a realizar incluyen:

- ¿ ¿Ha respetado el paciente y su grupo familiar el confinamiento?
- ¿El paciente ha presentado fiebre en los últimos 14 días mayor a $37,5^{\circ} \mathrm{C}$ ?

- ¿El paciente ha presentado síntomas respiratorios (tos, odinofagia, rinorrea, dificultad respiratoria) en los últimos 14 días?

- ¿El paciente ha presentado síntomas gastrointestinales (diarrea, vómitos, dolor abdominal) en los últimos 14 días?

- ¿El paciente ha presentado dolor o fatiga muscular, malestar general en los últimos 14 días?

- ¿El paciente ha presentado dolor de cabeza (cefalea) en los últimos 14 días?

- ¿Ha notado pérdida en el sentido del gusto o del olfato en los últimos 14 días?

- ¿El paciente o su representante han viajado a países de riesgo en los últimos 14 días?

- ¿El paciente ha presentado fiebre o cuadro respiratorio agudo en los últimos 14 días?

- ¿El paciente o su representante han estado en contacto estrecho con personas que presentan fiebre o cuadro respiratorio agudo en los últimos 14 días?

- ¿Han estado en contacto con alguien diagnosticado como sospechoso o confirmado COVID-19 en los últimos 14 días?

- ¿Cree usted que podría presentar una infección asintomática de COVID-19 actualmente?

- ¿El paciente ha pasado la enfermedad del COVID-19 y sigue en cuarentena o aislamiento? 
Si existe al menos una respuesta afirmativa en esta lista de chequeo se debe: contactar telefónicamente al médico o a la aseguradora del servicio de salud del paciente para activar el protocolo COVID-19 e iniciar aislamiento.

Nota : los niños tienden a presentar menos sintomatología que los adultos, todo paciente pediátrico debe considerarse portador asintomático potencial, a menos que se haya probado lo contrario

$\mathrm{Si}$ las respuestas son negativas, se procederá a realizar el procedimiento odontológico con sedación (paso 2).

Recomendaciones que se deben dar al paciente antes de acudir al procedimiento en el consultorio $20,26,27$ : (Anexo 2)

1. Antes de salir de casa deberá medir la temperatura corporal (temperatura $>37,5^{\circ} \mathrm{C}$ ).

2. Debera cumplir todas las medidas indicadas por las autoridades e instituciones de salud: tanto el niño como su representante deben utilizar mascarilla.

3. Vaya directo desde su casa hasta el consultorio, sin parar en lugares públicos.

4. Evite llevar accesorios como pulseras, relojes, aros o collares. Preferiblemente debe acudir únicamente con su cartera. Los bolsos, mochilas, relojes, pulseras, zarcillos, o cualquier elemento que no sea indispensable, debe dejarlo en casa (Juegos electrónicos, pantallas, tabletas).

5. Al ingresar al consultorio deberá lavar sus manos e higienizar con alcohol gel y luego realizar el lavado de manos y cara del niño.

6. El celular lo debe poner en silencio, debe limpiarlo con alcohol en el momento del lavado de manos y guardarlo, preferiblemente en una bolsa plástica con cierre fácil.

7. El paciente debe asistir máximo con un acompañante a la consulta. Además, en caso de ser posible es preferible que ingrese solo al consultorio dental. Las excepciones serán evaluadas junto al odontólogo tratante.

8. Para cumplir con el distanciamiento social, la cita será dada de forma puntual y en la sala de espera debe mantener una distancia mínima de 2 metros con otras personas.

9. Se les hará una toma de la temperatura con un termómetro digital, inmediatamente ingresen al consultorio para descartar la presencia de fiebre (temperatura $>37,5^{\circ} \mathrm{C}$ ).

10. Una vez en las instalaciones del consultorio odontológico, debe evitar desplazamientos innecesarios dentro del mismo.

11. Se le entregarán unas polainas desechables antes de entrar al área de la unidad odontológica, las cuales deben utilizar durante su estancia en el consultorio odontológico. ${ }^{16,29}$

12. Debe seguir las indicaciones médicas pre-sedación, cumpliendo con las horas indicadas de ayuno y la toma de medicamentos si fueron recetados.

13. Verifique que se explicaron los riesgos y han sido entendidos. Verifique que ha completado y firmado el consentimiento informado para el procedimiento odontológico y de sedación, y que están de acuerdo con los mismos. Idealmente deben ser llenados y diligenciados por completo por el paciente o su familia y de ser posible, enviarlos por correo 
electrónico. En muchos casos, los paciente ya han leído el consentimiento pero lo pueden diligenciar y firmar en físico directamente el día de la atención odontológica.

\section{Paso 2: Realización del tratamiento odontopedátrico bajo sedación}

Protocolo para la recepción del paciente en el consultorio

A la llegada del paciente :

1- Verifique que se cumplan las instrucciones entregadas el día anterior a la sedación: ayuno adecuado, un solo acompañante por paciente, el uso obligatorio de tapabocas convencional e historia clínica.

2- Se debe verificar el correcto diligenciamientodelos consentimientos informados y nuevamente resolver dudas e inquietudes del paciente o su familia antes de iniciar el procedimiento odontológico.

3- Si los pacientes lo desean o si la sala de espera no permite un " distanciamiento social adecuado" ( mínimo 2 metros de distancia), pueden esperar en un espacio abierto o fuera de las instalaciones donde puedan ser contactados por celular cuando sea su turno.

4- Se recomienda que sólo los pacientes asintomáticos respiratorios, con resultados negativos en el cuestionario para COVID-19 o los pacientes recuperados/curados sean atendidos en los consultorios odontológicos.

5- Tanto el paciente (adulto o niño) y su acompañante deben llegar con el tapabocas puesto y entrar directamente a lavado de manos, se les debe hacer una toma de temperatura en el momento del ingreso al consultorio con un termómetro digital (si es mayor de 37,5 ${ }^{\circ} \mathrm{C}$ no se debe realizar el procedimiento).

6- Se les debe entregar un par de cubre calzados desechables y explicarles la forma correcta en que se deben poner sobre el calzado.

7- Una vez en el consultorio, el pacientes debe permanecer sentado en la sala de espera hasta que sean llamados a la consulta. Queda prohibido deambular por los espacios comunes o asomarse a otras áreas. ${ }^{27,28}$

Equipo de protección personal para el odontólogo y el anestesiólogo que administra la sedación:

Todos los protocolos actuales recomiendan el uso de mascarillas con filtro tipo FFP2 (norma UNE-EN 149:2001+A1:2009 para Europa) o filtros N95 (según la normatividad de los Estados Unidos, certificado por la clasificación NIOSH - Instituto Nacional para la Salud y Seguridad Ocupacional-) para realizar procedimientos que requieran contacto directo con el paciente, exploración oral y que puedan generar aerosoles.

Equipo de protección personal específico (EPP) para sedaciones que generen aerosoles (PROTECCION TERCIARIA) durante el tratamiento odontológico (Tabla 4). Todo el personal de salud que estará participando en el área operatoria debe tener como mínimo este EPP.

EQUIPO DE PROTECCIÓN PERSONAL ESPECÍFICO (EPP): PARA TRATAMIENTOS QUE GENEREN AEROSOLES: RESPIRADOR (N95*, FFP2 O FFP3), LENTES, GORRO, PANTALLA FACIAL, BOTAS QUIRÚRGICAS, BATA MANGA LARGA ANTIFLUIDOS CON CUELLO CERRADO, 2 PARES DE GUANTES. 
Tabla 4. Equipo de Protección Personal Específico (EPP): para tratamientos que generen aerosoles

\begin{tabular}{|l|}
$\begin{array}{l}\text { Equipo de Protección Personal Específico (EPP): para tratamientos odontológicos bajo sedación } \\
\text { en el que se generen aerosoles }\end{array}$ \\
\hline Traje quirúrgico y zapatos cerrados que debe colocarse al llegar al consultorio. \\
\hline Cubre calzados \\
\hline Gorro \\
\hline Bata quirúrgica manga larga cuello cerrado ajustada por detrás u Overall. Deben ser antifluidos. \\
\hline $\begin{array}{l}\text { Respirador (N95, FFP2 o FFP3). Puede protegerlo para ser reutilizado colocando mascarilla } \\
\text { quirúrgica sobre el mismo }{ }^{31,32}\end{array}$ \\
\hline Lentes de protección \\
\hline Pantalla facial \\
\hline 2 pares de guantes \\
\hline
\end{tabular}

Equipo de protección personal básico reforzado (EPP) para sedaciones en tratamientos odontológicos que no generen aerosoles y el anestesiólogo pueda ubicarse a más de 1 metro del paciente (sedaciones paciente adulto): (Tabla 5)
EQUIPO DE PROTECCIÓN PERSONAL BÁSICO REFORZADO (EPP): PARA TRATAMIENTOS QUE NO GENEREN AEROSOLES: MASCARILLA QUIRÚRGICA, LENTES, GORRO, PANTALLA FACIAL, BOTAS QUIRÚRGICAS, BATA MANGA LARGA CUELLO CERRADO, GUANTES.

Tabla 5. Equipo de Protección Personal Específico (EPP): para tratamientos que no generen aerosoles

\section{Equipo de Protección Personal Específico (EPP): para tratamientos que no generen aerosoles}

Traje quirúrgico y zapatos cerrados que debe colocarse al llegar al consultorio.

\section{Cubre calzados}

\section{Gorro}

Bata quirúrgica manga larga cuello cerrado ajustada por detrás u Overall.

Deben ser antifluidos. Pueden ser reutilizables o descartables.

Mascarilla quirúrgica

Lentes de protección

Pantalla facial

Guantes 
En aquellas intervenciones que generen aerosoles (idealmente siempre), colocar protección ocular al paciente (gafas de protección).

\section{Si no tiene disponibilidad de EPP indicado para cada situación clínica NO realice la sedación.}

Los pasos para la correcta colocación y retiro de los elementos de protección personal deben estar impresos y en un lugar visible para ser leído y recordados por todos los participantes en la atención de un paciente durante la consulta odontológica. Ver anexo 3 (lista de chequeo 2).

\section{Elementos de Protección Personal - EPP.}

Los responsables del sistema de gestión de seguridad y salud en el trabajo de la empresa o consultorio deben definir los elementos de protección personal (EPP) indicados para la protección del personal de acuerdo con la labor que desempeña cada uno y debe además:

- Entregar los EPP y garantizar su disponibilidad y recambio.

- Informar las recomendaciones de uso eficiente de EPP.

- Verificar el uso de guantes cuando se va a entrar en contacto con el paciente, manipular elementos como residuos y para la desinfección del área del consultorio.

- Los EPP no desechables deberán ser lavados y desinfectados antes de ser almacenados en un área limpia y seca.

- Instalar recipientes adecuados para el destino final de los elementos de protección personal utilizados, y en el caso de las mascarillas N95 deben estar correctamente marcadas e identificadas.
- Designar un espacio donde los trabajadores puedan cambiarse de manera individual y donde puedan dejar sus implementos de protección personal debidamente limpios.

- Todo EPP que sea descartable debe ser desechado al terminar cada procedimiento con cada paciente dentro de bolsa roja de residuos peligrosos.

- $\quad$ El EPP no descartable debe ser lavado y desinfectado con alcohol al 70\%, soluciones de hipoclorito al 0,2\% o soluciones de amonio cuaternario (24).

Nota: Las mascarillas tipo FFP2 o N95 están diseñadas para un solo uso, pero muchas asociaciones médicas las utilizan hasta un máximo de 4 horas. En fecha muy reciente se ha publicado la eficacia de su esterilización mediante varios métodos ensayados (esterilización con vapor de peróxido de hidrogeno, mediante calor seco a $70{ }^{\circ} \mathrm{C}$ durante 30 minutos, o con calor húmedo a $121^{\circ} \mathrm{C}$ y meseta de esterilización de 15 minutos). Serían posibles 2 ó 3 esterilizaciones (por lo tanto 3-4 usos de la mascarilla) siempre que ésta se encuentre limpia e integra en su estructura. Para mantenerla limpia se recomienda colocar una mascarilla quirúrgica externa.

La mascarilla N95 puede tener un uso prolongado una vez se haya descontaminado o esterilizado, y siempre que no esté sucia, contaminada de fluidos o dañada. Estas se pueden guardar en bolsas de papel limpio y que se pueda sellar, en un lugar seco y rotular la fecha de su uso. Se puede volver a reutilizar 5 días después del último uso y verificar que esté integra, así como verificar los elásticos para garantizar un adecuado sello en la cara del personal que lo va utilizar. El respirador N95 es de uso personal, único 
y no transferible de una persona a otra, por lo tanto deben estar correctamente marcados e identificados. ${ }^{32,33}$

\section{Tapabocas convencional}

Estos elementos que cubren de manera no oclusiva la naríz y boca de las personas reducen la probabilidad de contacto con secreción nasal o saliva de otra persona. Los tapabocas convencionales tienen distintos diseños, entre ellos, los que se pliegan sobre la boca o nariz y los preformados, que no lo hacen.

Los tapabocas que no vienen preformados se humedecen más fácilmente y entran en contacto con mayor facilidad con secreción nasal o saliva de la persona. Para la colocación y uso del tapabocas se deben tener en cuenta las indicaciones del fabricante. ${ }^{30}$

Pasos para colocación y retiro de tapabocas convencionales:

- Lávese las manos antes de colocarse el tapabocas.

- El uso de los tapabocas debe seguir las recomendaciones del fabricante.

- Ajuste el tapabocas, si tiene elásticos, por detrás de las orejas, si es de tiras, se debe atar por encima de las orejas en la parte de atrás de la cabeza y las tiras de abajo por debajo de las orejas y se ata por encima del cuello.

- La correcta colocación debe cubrir la nariz y el mentón.

- La cara del tapabocas con color (impermeable) debe mantenerse como cara externa.

- Debido a su diseño, el filtrado no tiene las mismas características en un sentido y en otro, y su colocación errónea puede ser causante de una menor protección del profesional: La colocación con la parte impermeable (de color) hacia dentro puede dificultar la respiración del profesional y acúmulo de humedad en la cara. Por otro lado, dejar la cara absorbente de humedad hacia el exterior favorecerá la contaminación del tapabocas por agentes externos.

- Si el tapabocas tiene banda flexible en uno de sus lados, este debe ir en la parte superior para moldear la banda sobre el tabique nasal.

- No toque el tapabocas durante su uso. Si debiera hacerlo, lávese las manos antes y después de su manipulación.

- El tapabocas se puede usar durante un día de manera continua, siempre y cuando no esté roto, sucio o húmedo, en cualquiera de esas condiciones debe retirarse, eliminarse y colocar uno nuevo.

- Cuando se retire el tapabocas, hágalo desde las cintas o elásticos, nunca toque la parte externa de la mascarilla.

- Una vez retirada, doble el tapabocas con la cara externa hacia dentro y deposítela en una bolsa de papel o basura.

- No reutilice el tapabocas.

- Inmediatamente después de retirar el tapabocas realice lavado de manos con agua y jabón.

- El tapabocas se debe mantener en su empaque original si no se va a utilizar o en bolsas selladas, no se recomienda guardarlos sin empaque en el bolso, o bolsillos sin la protección porque se pueden contaminar, romper o dañar.

- Los tapabocas no se deben dejar sin protección encima de cualquier superficie por el riesgo de contaminarse. 
Recomendaciones en el momento de la atención de un paciente en el consultorio de odontología que requiere sedación:

1- Verificar que todo el personal involucrado en la atención del paciente tenga los EPP (se hará acta de entrega de EPP no descartable como pantalla facial y gafas protectoras).

2- Utilizar preferiblemente la unidad odontológica que tenga más luz solar y ventilación.

3- Disminuir al máximo el personal de salud dentro del consultorio: si el paciente es adulto, sólo deberá ingresar el paciente, el odontólogo, la auxiliar de odontología; y a los pies del paciente se ubica el médico anestesiólogo y la auxiliar de sedación. En el caso de paciente pediátrico, podrá ingresar con un acompañante, mientras se duerme, y luego deberá esperar fuera del consultorio hasta que el procedimiento haya finalizado. Para el caso particular de los niños, el médico anestesíologo se sentará a la cabecera del paciente al frente del odontólogo para monitorizar y vigilar de cerca la vía aérea.

4- Confirmar limpieza de todas las superficies, el equipo de monitoreo y los contenedores de transporte con las soluciones desinfectantes recomendadas antes de ingresar a la unidad odontológica.

5- Verificar el lavado de manos con jabón antiséptico y posterior aplicación de gel alcoholado.

6- Proteger y cubrir la unidad odontológica, los monitores y los contenedores del equipo de sedación con película plástica de protección (papel film), los cuales se deben retirar al finalizar el procedimiento (éste paso no exime de la limpieza y desinfección de todas las superficies de los equipos con solución desinfectante).

7- Realizar un nuevo lavado de manos con agua y jabón más gel alcoholado antes de la colocar los EPP.

8- La colocación de los elementos de protección personal requiere un orden específico y debe quedar registrado en la lista de chequeo 2 (anexo 3).

Vestido quirúrgico o uniforme de uso exclusivo para el consultorio

Lavado de manos con jabón antiséptico o clorhexidina, colocación de gel alcoholado

a. Cubre calzados

Higiene de manos con gel alcoholado.

b. Gorro

c. Bata quirúrgica manga larga cuello cerrado ajustada por detrás u Overall

d. 1er. par de guantes

e. Respirador N95* (cubrir con mascarilla quirúrgica.)

f. Lentes de protección

Higiene de manos con gel alcoholado.

g. Pantalla facial

h. 2do. par de guantes

Higiene de manos con gel alcoholado.

9- Durante el procedimiento no debe tocarse ningún implemento facial.

10- Antes de comenzar la atención, el paciente debe hacer enjuague con peróxido de hidrogeno al $1 \%$ o iodopovidona al $0,2 \%$ durante 1 minuto (recuerde descartar y confirmar con el paciente o su familia, las posibles alergias al yodo). Para los pacientes pediátricos se debe 
disminuir el riesgo de ingestión de los antisépticos bucales, por lo cual sólo se realiza limpieza peribucal con gasa impregnada en peróxido de hidrógeno $1 \%$.

11- Justo antes de iniciar el procedimiento se cubre el paciente con sabana plástica o campo quierúrgico desechable que sólo tiene un orificio para ubicar la zona de la boca (será desechada en bolsa roja al finalizar el procedimiento). Preferiblemente y se colocará acetatos transparentes con orificio para introducir la pieza de mano y la succión de 15 x $10 \mathrm{cms}$ cada una, para poner barrera física pero que permita la visibilidad por aerosoles, éstas serán desechadas al final del procedimiento en bolsa roja.

12- Durante el tratamiento odontológico para manejo de caries se recomienda técnicas que no generen aerosoles, con base científica en la literatura y que no requieran múltiples citas de tratamiento. Preferiblemente usar piezas de mano rotatorias de baja velocidad, irrigar por goteo o humedecer con torundas de algodón, hacer una restauración atraumática con cucharilla, eliminación selectiva de la dentina cariada, aplicar diamino fluoruro de plata y restaurar con técnica de Hall.

13- Usar el dique de goma para procedimientos operatorios $y$ endodoncias, siempre que sea posible. Este dispositivo reduce en un $70 \%$ la concentración de aerosoles.

14- Utilizar la succión de alta en todo momento para evitar acumulo de secreciones.

15- Mantener trabajo a cuatro manos, con el fin de agilizar el procedimiento.
16- Evitar abrir la puerta del consultorio mientras se realiza el procedimiento.

17- Al terminar el tratamiento, se debe hacer desinfección del espacio aéreo del consultorio con desinfectante en aerosol, esperar 2 minutos antes de abrir la puerta. Se debe esperar la recuperación completa del paciente, hasta que pueda ser trasladado a la sala de espera, la cual debe estar vacía, o en el caso de los niños, deberá permanecer con su familiar o acompañante. El personal de salud debe retirarse el EPP antes de salir del consultorio.

18- Una vez el paciente este completamente despierto, debe hacerse un último lavado de manos previo a la salida del consultorio.

19- El material biológico y cortopunzante debe ser desechado en los contenedores correspondientes (bolsa roja y guardián). La esterilización del material debe seguir las técnicas habituales debido a que son efectivas en la destrucción de las partículas virales.

20- Si fue absolutamente necesario usar piezas de mano de alta velocidad con producción de aerosoles, se debe esperar 3 horas ants de ingresar el próximo paciente. Los aerosoles contaminados se mantienen en el ambiente de la unidad entre 30 minutos y 2 horas, por lo que el virus puede sobrevivir en estos ambientes cargados de aerosoles. ${ }^{26-30}$

21- Todo el personal debe cumplir las pautas para el correcto retiro de los EPP después de cada procedimiento, en el siguiente orden :

a. Retirar primer par de guantes 
Higiene de manos (primer par de guantes) con gel alcoholado

b. Retirar la pantalla facial y colocarla en una mesa o área específica para su desinfección

c. Retirar la bata desechable de atrás hacia adelante y desecharla en bolsa roja

\section{Higiene de manos con gel alcoholado}

d. Retirar gafas protectoras (desinfección con alcohol al $70 \%$ o amonio cuaternario)

\section{Higiene de manos con gel alcoholado}

e. Retirar la máscarilla convencional y desecharla en bolsa roja

f. Retirar la mascarilla N95, la cual se debe inspeccionar para descartar que este detriorada o contaminada con fluidos o material particulado del paciente. Si esta en buenas condiciones, se debe guardar inmediatamente en bolsa de papel, sellarla y rotularla con la fecha de uso.

\section{Higiene de manos con gel alcoholado}

g. Retirar el gorro

h. Retirar cubre calzados

i. Retirar el segundo par de guantes y desecharlos en bolsa roja

Realizar lavado de manos con jabón desinfectante y posterior aplicación de gel alcoholado.

22- Finalmente, se debe hacer una inspección para identificar humedad o fluidos sobre el vestido quirúrgico o el uniforme. Si es así, se debe cambiar de vestido quirúrgico y guardar en bolsa roja hasta que pueda ser correctamente desinfectado y lavado con agua y jabón en un sitio seguro que no produzca contaminación de otros vestuarios.

\section{Recomendaciones después de culminado el tratamiento bajo sedación}

Recomendaciones para el paciente (Anexo 2):

Terminado el tratamiento, deberá realizar el lavado de manos y cara del niño y del representante. Posteriormente deben colocar sus mascarillas nuevamente. Una vez tolerada la vía oral y determinado que puede ser dado de alta, se indica el retiro del consultorio.

Deben serle dadas por escrito las recomendaciones postanestésicas al paciente

Para el pago de la consulta, es preferible utilizar medios electrónicos.

Debe mantener el distanciamiento social y dirigirse a su hogar. Al llegar a casa dejar sus zapatos y los del paciente en la entrada, tanto el paciente como el acompañante deben dirigirse directo al baño, retirar sus mascarillas, lavarse manos y cara. Las mascarillas deben desecharse en un recipiente cerrado al interior de una bolsa.

Debe seguir las indicaciones del odontólogo referente a cuidados y toma de medicamentos y hacer el seguimiento conjunto de la evolución.

\section{Desinfección de superficies:}

Entre cada procedimiento de debe realizar limpieza de todas las superficies localizadas a un radio de 2 metros de la unidad odontológica si no hubo aerosoles, y de 5 metros si hubo aerosoles. La auxiliar de sedación debe realizar limpieza y desinfección de los monitores y los contenedores que se ingresaron al 
consultorio con soluciones de hipoclorito, alcohol o amonio cuaternario diseñados para equipos médicos, luego de retirar y desechar la película plástica. Recordar que la vida media del coronavirus en superficies como el acero es de 48 horas y en el plástico hasta de 5 días. $^{33}$ (Tabla 6).

El personal que realiza el procedimiento de limpieza y desinfección debe utilizar los elementos de protección personal (usar guantes, delantal y tapabocas).

- Realizar la limpieza de áreas y superficies retirando el polvo y la suciedad, con el fin de lograr una desinfección efectiva.

- Los paños utilizados para realizar la limpieza y desinfección deben estar limpios.

- El personal de limpieza debe lavar sus manos antes y después de realizar las tareas de limpieza y desinfección, así mismo se deben utilizar guantes $\mathrm{y}$ seguir las recomendaciones del fabricante de los insumos a utilizar.

- Garantizar que el proceso de limpieza y desinfección se realice de manera segura y con los elementos necesarios dependiendo de las áreas o de las zonas

Tabla 6. Persistencia del coronavirus en las superficies.

\begin{tabular}{|l|c|}
\hline \multicolumn{2}{|c|}{ Persistencia del coronavirus en las superficies } \\
\hline Material & Días /Horas \\
\hline Plástico & 5 \\
\hline Papel & $4-5$ \\
\hline Vidrio & 4 \\
\hline Madera & 4 \\
\hline Acero & 2 (48 horas) \\
\hline Guantes (látex/nitrilo) & - (8 horas) \\
\hline Aluminio & $-(2-8$ horas $)$ \\
\hline
\end{tabular}

de desplazamiento y trabajo con los productos desinfectantes indicados. Revise las recomendaciones de cada fabricante para realizar el adecuado proceso de limpieza.

- Las superficies del cuarto de baño y el sanitario deben limpiarse y desinfectarse al menos una vez al día.

- Elimine los guantes y paños en una papelera después de usarlos, si sus guantes son reutilizables, antes de quitárselos lave el exterior con el mismo desinfectante limpio con que realizó la desinfección de superficies, déjelos secar en un lugar ventilado. Al finalizar retirese los EPP con los que realizo la limpieza.

- Utilizar desinfectantes o alcohol al $70 \%$ para la limpieza de los objetos, superficies y materiales de uso constante..$^{30}$

\section{Protocolo para la interacción en tiempos de alimentación del personal del consultorio}

En los tiempos de alimentación, se debe limitar el número de personas que realizan esta actividad de forma simultánea para garantizar la distancia social.

Establecer turnos $\mathrm{u}$ horarios flexibles de alimentación y descanso para evitar aglomeraciones.

Se debe evitar tomar los alimentos en zonas que no se encuentren diseñadas para tal fin.

En caso, que la alimentación no sea suministrada por la empresa y el trabajador se encargue de calentar su comida en hornos microondas, se debe disponer de paños y alcohol glicerinado que permitan asear el panel de control 
de este entre cada persona que lo utiliza, o designar a alguien que se encargue de efectuar la manipulación de los hornos.

Antes de tomar los alimentos, es necesario realizar el siguiente protocolo:

- Lavar las manos con agua y jabón.

- Retirar el tapabocas

- Lavar nuevamente las manos con agua y jabón o aplicar gel alcoholado.

- Disponer las mesas con una distancia entre las mismas de 2 metros y colocar solamente el número de sillas que permita asegurar una distancia mínima entre los trabajadores de 2 metros a la hora de la alimentación.

- Al finalizar el consumo de alimentos es necesario realizar el lavado de manos con agua y jabón y utilizar un nuevo tapabocas para retomar las labores. ${ }^{30}$

\section{Desplazamiento desde y hacia el lugar de trabajo}

Para asegurar la llegada a tiempo y evitar el contagio en los desplazamientos de los trabajadores de la clínica o consultorio se deben aplicar las siguientes recomendaciones:

1. Capacitar en el cumplimiento de los protocolos para los traslados, especialmente los de uso de transporte público, establecidos por las autoridades competentes.

2. Si los desplazamientos se realizan en medios de transporte masivo, se deberá hacer uso del tapabocas y en la medida de lo posible guantes de látex, nitrilo o caucho, procurando mantener distancia mínima de dos metros entre las personas.

3. Cuando el transporte sea suministrado por la clínica o empresa del consultorio, se debe garantizar que el vehículo se encuentre limpio y desinfectado sobre todo en las superficies con las cuales los pasajeros van a tener contacto, tales como manijas de puertas y ventanas, cinturones de seguridad y asientos, entre otras. El procedimiento de limpieza y desinfección debe realizarse nuevamente una vez haya terminado la ruta de los trabajadores hacia el trabajo o al lugar de residencia. Se debe evitar realizar paradas no autorizadas o innecesarias.

4. Se recomienda guardar una silla de distancia entre un pasajero y otro.

\section{Protocolo de llegada a casa del personal de salud}

Al llegar a casa, todo el personal de salud (odontólogo, anestesiólogo y auxiliares) deben adoptar las medidas de seguridad que reduzcan la posibilidad de contaminación y contagio en el hogar:

Retirar el calzado y desinfectarlo. Se recomienda tener un tapete impregnado de alcohol o hipoclorito para desinfectar la suela de los zapatos antes de ingresar a la casa.

Evitar saludar con beso, abrazo y dar la mano y buscar mantener siempre la distancia de más dedos metros entre personas.

Dejar todos los accesorios como bolso, llaves y reloj en una caja aparte en la entrada de la casa para su posterior desinfección.

Retirar el uniforme dejándolo en una bolsa independiente, para lavarlo posteriormente separado de la ropa de los demás familiares.

Ducharse inmediatamente.

Mantener la casa ventilada, limpiar y 
desinfectar áreas, superficies y objetos de manera regular.

Si hay alguna persona con síntomas de gripa en la casa, tanto la persona con síntomas de gripa como quienes cuidan de ella deben utilizar tapabocas de manera constante en el hogar, y se debe reportar al sitio de trabajo.

Nota: si el personal de salud presentan síntomas compatibles con infección por COVID-19, debe seguir los protocolos establecidos por sus respectivas aseguradoras en salud, informando de manera inmediata y avisar a la administradora de riesgos profesionales (ARL) para evaluar si se puede tratar de un contagio dentro de la práctica profesional. ${ }^{30}$

Medidas en coordinación con Administradoras de Riesgos Laborales ARL

Las administradoras de riesgos laborales son entidades públicas o privadas que se encargan de vigilar las normas y procedimientos destinados a prevenir, proteger y atender a los trabajadores de los efectos de las enfermedades y accidentes que pueden ocurrir en los trabajadores como consecuencia de su desempeño laboral. En la situación actual de la pandemia se encargan de verificar si el personal de la salud ha contraído la infección como consecuencia de la atención de pacientes sospechosos o confirmados de COVID-19.

Por esta razón se debe coordinar con estas entidades las siguientes medidas:

- Incluir en la identificación de factores de riesgo biológico para contagio del coronavirus las actividades de mayor exposición y de este modo determinar los controles a implementar, entre ellos la distribución de espacios de trabajo y ubicación del personal para el distanciamiento físico y disminuir el riesgo de exposición.

- Diseñar con la asesoría de la Administradoras de Riesgos Laborales - ARL la lista de chequeo para identificar potenciales riesgos $\mathrm{y}$ establecer los controles operacionales necesarios antes del inicio de la actividad laboral.

- Las ARL deberán disponer de un equipo técnico responsable para orientar a sus empresas afiliadas en la gestión del riesgo laboral por exposición a COVID-19.

- Dar aplicación a los protocolos, procedimientos y lineamientos adoptados por las autoridades de cada país conforme a sus funciones de asesoría y asistencia técnica.

- Las ARL deberán suministrar asistencia técnica para la vigilancia de la salud de los trabajadores expuestos al riesgo laboral de COVID-19 y orientar a las clínicas o instituciones prestadoras de salud sobre la gestión del riesgo laboral de los trabajadores vulnerables a la infección.

- Orientar a los empleadores y trabajadores afiliados sobre la postura, uso, porte adecuado, retiro, manipulación, disposición y eliminación de los elementos de protección personal, según las instrucciones de las autoridades sanitarias.

- Responder de manera ágil y oportuna 
a las solicitudes de las empresas referentes al control del riesgo laboral por COVID-19.

\section{Pasos a seguir en caso de presentar una persona con síntomas compatibles con COVID-19.}

Si una persona presenta síntomas de COVID-19 como: fiebre, tos, dificultad para respirar se cumplirá con el siguiente procedimiento:

Comunicar inmediatamente al jefe inmediato (odontólogo o médico) encargado del consultorio la presencia de síntomas.

Verificar el uso correcto de tapabocas y deberá ubicarlo en una zona de aislamiento identificada previamente.

Registrar la encuesta de factores de riesgos para identificar el posible foco de contagio: viajes a zonas con infección o contacto estrecho con un caso confirmado o sospechoso de COVID-19.

La empresa debe reportar el caso a la EPS (entidades promotoras de salud o aseguradoras) y a la secretaría de salud que corresponda para que evalúen su estado de salud. Ellos determinarán si se debe trasladar a su casa con un aislamiento preventivo para síntomas leves y en el caso de dificultad para respirar, lo deben trasladar a un centro médico en una ambulancia de forma inmediata.

Si el trabajador se encuentra en su casa y presenta síntomas de fiebre, tos, dificultad para respirar o un cuadro gripal, deberá contactarse telefónicamente con su jefe inmediato para poner en su conocimiento la situación y tanto el empleador como el trabajador deberán reportar el caso a la EPS y a la secretaria de salud que corresponda para que evalúen su estado de salud.

Realizar una lista con todas las personas que han estado en contacto estrecho (a menos de 2 metros por más de 15 minutos) con el caso confirmado en los últimos 14 días. Dicha lista se entregará a la secretaria de salud correspondiente para dar seguimiento y los contactos identificados estarán en aislamiento preventivo por 14 días. ${ }^{30}$

\section{Conclusión}

El diseño de este protocolo esta basado en la evidencia científica hasta ahora publicada asociada a las medidas adoptadas por los diferentes gobiernos de la región que buscan mitigar y disminuir el riesgo de trasmisión y contagio del COVID-19. Busca desarrollar todas las estrategias necesarias para garantizar la seguridad del paciente y del personal de salud para disminuir al mínimo el riesgo de contagio por coronavirus durante la atención médica-odontológica.

Esta sujeto a cambios de acuerdo con las directrices indicadas por los entes gubernamentales y según la evidencia científica publicada constantemente.

Al final de este documento encontrará las listas de chequeo que facilitan la implementación deesteprotocoloypermite confirmar que estén todos los elementos necesarios para hacer una atención segura en el área del consultorio odontológico. $\mathrm{Su}$ correcto diligenciamiento cada día permitirá disminuir los errores y tomar las medidas necesarias para identificar cualquier falla en la atención del paciente. 


\section{Autores}

Desarrollo de este artículo liderado por: Piedad Cecilia Echeverry Marin (Colombia), Adriana Maria Rubiano Pinzon (Colombia), como parte del Equipo Interdisciplinario COVID-19 de la Asociación Latinoamericana de Odontopediatría.

Equipo Interdisciplinario COVID-19 de la Asociación Latinoamericana de Odontopediatría: Jenny Abanto (Brasil), Mariana Armada (Argentina), Paola Beltri (España), Marisol Carrillo Tabakman (Paraguay), Haydée Casaretto (Argentina), Jorge Luis Castillo (Perú), Mónica Gladys Cesetti (Argentina), Bertha Angélica Chávez González (Perú), Ana Claudia Rodrigues Chibinski (Brasil), Salomon Alberto Cohen (Argentina), Olga Cortés Lillo (España), Luzia Ana Da Silva de Carballo (Venezuela), Gonzalo De la Fuente Alvarez (Chile), Renée Di Nallo (Argentina), María Débora Elizabeth Dricas (Argentina), Sandra Echevarria (Brasil), Piedad Cecilia Echeverry Marin (Colombia), Laura Fedelli (Argentina), Carlos Flores-MIr (Canadá), Andrea Virgina González Carfora (Chile), Lina María Hernández Salas (Colombia), Francisco
José Hernández Restrepo (Colombia), Maria Teresa Ibañez Rodriguez (Bolivia), José Carlos Pettorossi Imparato (Brasil), Alejandra Lipari Valdés (Chile), Daniela Madrigal López (Costa Rica), Daniela Catalina Martínez Camus (Chile), María Gabriela Martínez Vásquez (Venezuela), A. Carolina Medina Díaz (Venezuela), Kelly Maria Silva Moreira (Brasil), Elías M. Morón (Estados Unidos de América), Martha Mutis (Estados Unidos de América), Camila Palma (Perú), Gladys Mabel Peña (Argentina), Adriana Pistochini (Argentina), Paloma Planells (España), Gabriel Politano (Brasil), Matias RiosErazo (Chile), Adriana Maria Rubiano Pinzon (Colombia), Karla Mayra Rezende (Brasil), Rosa Gabriela Rondón (Venezuela), Gabriela Scagnet (Argentina), Rosemary Sogbe de Agell (España), Marina Tavares Costa Nóbrega (Canadá), Jorgelina Valente (Argentina), Ernesto Venegas De Herrera (República Dominicana), Rosa Helena Wanderley Lacerda (Brasil), Ana Clara Zabala (Argentina), Gabriel Zambrano (Venezuela).

Información completa del Equipo Interdisciplinario COVID-19 de la Asociación Latinoamericana de Odontopediatría

\section{Referencias bibliográficas}

1. Alocución de apertura del director general de la OMS en la rueda de prensa sobre el COVID-19 celebrada el 11 de marzo de 2020. Consultada en junio 2 de 2020. Disponible en: https://www.who.int/es/dg/speeches/detail/who-director-general-s-opening-remarks-at-the-media-briefing-on-covid-19--11-march-2020

2. Rueda de prensa semana sobre la situación de COVID-19 en la región de las américas. Consultado junio 2 de 2020. Disponible en: https://www.paho.org/es/medios/rueda-prensa-semanal-sobre-situacion-covid-19-region-americas

3. Ruta de atención para procedimientos de odontología pediátrica durante la etapa de confinamiento o cuarentena de a pandemia COVID-19. Volumen 10, número 2, año 2020. Asociación Latinoamericana de Odontopediatría (ALOP). Consultado junio 3 de 2020. Disponible en: https://www.revistaodontopediatria.org/ediciones/2020/2/art-1/

4. Res 385 del 12 de marzo de 2020 Por la cual se declara la emergencia sanitaria por causa del coronavirus COVID-19 y se adoptan medidas para hacer frente al virus MinSalud.Colombia. Consultado abril 28 de 2020. Disponible en: https://www.minsalud.gov.co/sites/rid/Lists/BibliotecaDigital/RIDE/DE/DIJ/resolucion-385-de-2020.pdf

5. Robles Daniel, Rodrigues HectorJ. El COVID-19 y la consulta dental: información y consejos. Gaceta Dental. 18 de marzo de 2020. Consultado en abril 28 de 2020. Disponible en: https://gacetadental. com/2020/03/el-covid-19-y-la-consulta-dental-informacion-y-consejos-95967/

6. Lineamiento para las acciones de prevención y contención en control de infecciones asociadas a la atención en salud frente a casos sospechosos y confirmados de COVID-19 para instituciones prestadoras de servicios de salud en la ciudad de Bogotá ante situación de emergencia sanitaria.Secretaria Distrital de Salud Bogotá.Asociacion Colombiana de Infectología Capítulo Central. Subdireccion de Vigilancia en Salud Pública . 18 de Marzo de 2020. Disponible en: http://www.saludcapital.gov.co/Covid_legal/Circular_038_Sds_05_2020_Prev_infc.pdf 
7. Covid-19 Aerosoles : Contaminación en el Box dental. Colegio de Odontólogos de Cataluña-España. 18 de Marzo de 2020. Consultado 28 de abril de 2020. Disponible en: http://www.coec.cat/es/noticies/ covid-aerosoles

8. Zou, Lirong. Ruan, Feng. Huang, Mingxing. Liang, Lijun. Huang, Huitao. Hong, Zhongsi. Yu, Jianxiang et al. SARS-CoV-2 Viral Load in Upper Respiratory Specimens of Infected Patients. N. Engl. J. Med., 2020. 382 (12):1177-1179.

9. Coronavirus (Nuevo coronavirus 2019-nCoV). Consultado junio 3 de 2020. Disponible en: https://www. who.int/es/health-topics/coronavirus

10. Rothan HA, Byrareddy SN. The epidemiology and pathogenesis of coronavirus disease (COVID-19) outbreak. J Autoimmun. 2020;109:102433. doi:10.1016/j.jaut.2020.102433

11. Kannan S, Shaik Syed Ali P, Sheeza A, Hemalatha K. COVID-19 (Novel Coronavirus 2019) - recent trends. Eur Rev Med Pharmacol Sci. 2020;24(4):2006-2011. doi:10.26355/eurrev_202002_20378

12. Sohrabi C, Alsafi Z, O'Neill N, et al. World Health Organization declares global emergency: A review of the 2019 novel coronavirus (COVID-19) [published correction appears in Int J Surg. 2020 May;77:217]. Int J Surg. 2020;76:71-76. doi:10.1016/j.ijsu.2020.02.034

13. Rodriguez-Morales AJ, Cardona-Ospina JA, Gutiérrez-Ocampo E, et al. Clinical, laboratory and imaging features of COVID-19: A systematic review and meta-analysis. Travel Med Infect Dis. 2020;34:101623. doi:10.1016/j.tmaid.2020.101623

14. Vaduganathan, M., Vardeny, O., Michel, T., McMurray, J. J., Pfeffer, M. A., \& Solomon, S. D. (2020). Renin-angiotensin-aldosterone system inhibitors in patients with Covid-19. New England Journal of Medicine, 382(17), 1653-1659. DOI: 10.1056/NEJMsr2005760

15. Guan W, Ni Z, Hu Y, et al. Clinical characteristics of coronavirus disease 2019 in China. N Engl J Med. DOI: 10.1056/NEJMoa2002032.

16. Covid-19 Atencion Odontológica programada inicial . Ministerios de Salud -Argentina. 22 de abril 2020 http://www.msal.gob.ar/images/stories/bes/graficos/0000001937cnt-covid-19-recomendaciones-atencion-odontologica-programada.pdf

17. Dental Tribune latín American.Comunicado de la Federación Odontológica al gremio Odontológico sobre COVID-19 .16 de Marzo de 2020 https://la.dental-tribune.com/news/normas-para-pacientes-y-acompanantes-2-2/

18. Dental tribune Latín American.El COVID-19-Ese enemigo invisible.31 de Marzo 2020. https://a.dental-tribune.com/news/el-covid-19-ese-enemigo-invisible

19. Odontología en tiempos de pandemia SARS-Co2 y COVID-19. Castellanos, Jaime. Instituto de Virología de la Universidad del Bosque. Bogotá, Colombia. Consultado en abril 28 de 2020. Disponible en: https:// ucu.edu.uy/es/node/47875

20. Teleodontología: Aplicación a la Odontopediatría durante la pandemia COVID-19. Consultado junio 3 de 2020. Disponible en: https://www.revistaodontopediatria.org/ediciones/2020/2/art-3/

21. Echeverry PC, Rubiano A. Sedación. En: Jaramillo J, Echeverry PC, Gomez JM. Tratado de Anestesiología Pediátrica. Sociedad Colombiana de Anestesiología y Reanimación. Bogotá, Mayo 2015. ISBN 978-9588873-18-3. Capítulo 23. Páginas 550 - 577

22. Souza RCC, Costa OS, Costa LR. Dental sedation precautions and recommendations during the COVID-19 Pandemic. Rev Bras Odontol. 2020;77:e1788. https://odontopediatria.cl/wp-content/uploads/2020/04/ Souza-et-al-2020-Dental-sedation-Covid-19.pdf.pdf

23. Tait AR, Malviya S. Anesthesia for the child with an upper respiratory tract infection: still a dilemma? Anesth Analg. 2005;100(1):59-65. Review.

24. Rubiano A, Hernandez FJ, Rincón JE, Vasquéz LM, Cardenas JM. Odontología y Cirugía Oral. En: Jaramillo J, Echeverry PC, Gomez JM. Tratado de Anestesiología Pediátrica. Sociedad Colombiana de Anestesiología y Reanimación. Bogotá, Mayo 2015. ISBN 978-958-8873-18-3. Capítulo 39. Páginas: 154 -174.

25. CDC: https://www.cdc.gov/infectioncontrol/pdf/guidelines/disinfection-guidelines- H.pdf https://www. cdc.gov/coronavirus/2019-ncov/hcp/dental-settings.html

26. Lineamientos de bioseguridad para adaptar en los sectores diferentes a salud. Consultado abril 25 de 2020. Disponible en: file://Users/piedadecheverry/Downloads/GIPS24guia\%20de\%20bioseguridad\%20 \%20sectores\%20no\%20salud.pdf

27. Plan de acción en la consulta en el periodo posterior a la crisis COVID19 en cirugía plástica, estética y reparadora. Consultado abril 27 de 2020. Disponible en: https://cdn2.hubspot.net/hubfs/7062317/file/ covid-19/COVID-19-Linee_guida_SECPRE.pdf 
28. Asociación Colombiana de Infectología. Consenso Colombiano de atención, diagnóstico y manejo de la infección por SARS-CoV-2/COVID-19 en establecimientos de atención de la salud. Segunda Edición, Recomendaciones basadas en el consenso de expertos e informadas en la evidencia. Infectio. 2020; 24 (3): S2

29. Lineamiento para la atención de urgencias por alteraciones de la salud bucal, durante el period de la pandemia por SARS-COV-2 (COVID-19). Consultado en mayo 5 de 2020. Disponible en: https://www. minsalud.gov.co/Ministerio/Institucional/Procesos\%20y\%20procedimientos/GIPS26.pdf

30. Resoluccion 666 de 2020. Por medio de la cual se adopta el protocolo general de bioseguridad para mitigar, controlar y realizar el adecuado manejo de la pandemia del COVID-19 en Colombia. Consultado en abril 28 de 2020. Disponible en: https://id.presidencia.gov.co/Documents/200424-Resolucion-666-MinSalud.pdf

31. Ather A, Patel B, Ruparel NB, Diogenes A, Hargreaves KM. Coronavirus Disease 19 (COVID- 19): Implications for Clinical Dental Care. J Endod. 2020 Apr 6. pii: S0099- 2399(20)30159-X. doi: 10.1016/j. joen.2020.03.008.

32. European Centre for Disease Prevention and Control. Cloth masks and masks sterilization as options in case of shortage of surgical masks and respirators. 26 March 2020. https://www.ecdc.europa.eu/sites/ default/files/documents/Cloth-face- masks-in-case-shortage- surgical-masks-respirators2020-03-26.pdf

33. Van Straten, B.J., van den Dobbelsteen, J.J., Horeman, T. Steam sterilization of used disposable masks with respect to COVID-19 shortages. http://resolver.tudelft. nl/uuid:078a3733- 84d6-4d4a-81e6-74210c7fed78

34. Kampf, G., Todt, D., Pfaender, S., \& Steinmann, E. (2020). Persistence of coronaviruses on inanimate surfaces and its inactivation with biocidal agents. Journal of Hospital Infection. https://doi.org/10.1016/j. jhin.2020.01.022

Recibido 24/05/2020

Aceptado: 21/06/2020

Correspondencia: e-mail: editor@revistaodontopediatria.org 


\title{
Anexo 1
}

\section{AL@ ASOCIACIÓN LATINOAMERICANA DE ODONTOPEDIATRÍA}

\author{
CUESTIONARIO PRE-CONSULTA ODONTOPEDIÁTRICA DE SEDACIÓN \\ DURANTE LA PANDEMIA COVID-19
}

Odontólogo Tratante:

\begin{tabular}{|c|c|c|c|}
\hline \multirow{8}{*}{ Datos Personales } & \multicolumn{3}{|l|}{ Nombre del Solicitante: } \\
\hline & \multicolumn{3}{|l|}{ DNI / Identificación representante o tutor: } \\
\hline & \multicolumn{3}{|l|}{ Teléfono de contacto: } \\
\hline & \multicolumn{3}{|l|}{ Correo electrónico: } \\
\hline & \multicolumn{3}{|l|}{ Nombre del Paciente: } \\
\hline & \multicolumn{3}{|l|}{ Edad: } \\
\hline & Relación con el paciente: $\square$ Padre/Madre & Tutor Legal & Otro \\
\hline & \multicolumn{3}{|l|}{ Fecha de la Consulta: } \\
\hline
\end{tabular}

Procedimiento Odontológico a realizar:

¿Presenta antecedentes médicos relevantes?

$\square \mathrm{SI} \quad \square \mathrm{NO}$

Describa

¿Ha respetado el paciente y su grupo familiar el confinamiento?

¿El paciente ha presentado fiebre en los últimos 14 días mayor a $37,5^{\circ} \mathrm{C}$ ?

¿El paciente ha presentado síntomas respiratorios (tos, odinofagia, rinorrea, dificultad respiratoria) en los últimos 14 días?

¿El paciente ha presentado síntomas gastrointestinales (diarrea, vómitos, dolor abdominal) en los últimos $14 \quad \square$ SI $\quad \square$ NO días?

¿El paciente ha presentado dolor o fatiga muscular, malestar general en los últimos 14 días?

¿El paciente ha presentado dolor de cabeza (cefalea) en los últimos 14 días?

¿Ha notado pérdida en el sentido del gusto o del olfato en los últimos 14 días?

¿El paciente o su representante han viajado a países de riesgo en los últimos 14 días?

¿El paciente ha presentado fiebre o cuadro respiratorio agudo en los últimos 14 días?

¿El paciente 0 su representante han estado en contacto estrecho con personas que presentan fiebre 0 cuadro respiratorio agudo en los últimos 14 días?

¿Han estado en contacto con alguien diagnosticado como sospechoso o confirmado COVID19 en los últimos

14 días?

¿Cree usted que podría presentar ina infección asintomática de COVID-19 actualmente?

¿El paciente ha pasado la enfermedad del Covid-19 y sigue en cuarentena o aislamiento?

\begin{tabular}{|l|l|}
$\square \mathrm{SI}$ & $\square \mathrm{NO}$ \\
$\square \mathrm{SI}$ & $\square \mathrm{NO}$ \\
\hline$\square \mathrm{SI}$ & $\square \mathrm{NO}$ \\
\hline$\square \mathrm{SI}$ & $\square \mathrm{NO}$ \\
$\square \mathrm{SI}$ & $\square \mathrm{NO}$ \\
$\square \mathrm{SI}$ & $\square \mathrm{NO}$ \\
$\square \mathrm{SI}$ & $\square \mathrm{NO}$ \\
\hline$\square \mathrm{SI}$ & $\square \mathrm{NO}$ \\
\hline$\square \mathrm{SI}$ & $\square \mathrm{NO}$ \\
\hline$\square \mathrm{SI}$ & $\square \mathrm{NO}$ \\
\hline$\square \mathrm{SI}$ & $\square \mathrm{NO}$ \\
$\square \mathrm{SI}$ & $\square \mathrm{NO}$ \\
$\square \mathrm{SI}$ & $\square \mathrm{NO}$ \\
\hline
\end{tabular}

Si todas las respuestas son negativas, por favor siga las siguientes recomendaciones y confirme a su Odontólogo y/o Anestesiólogo para programar su procedimiento odonto-quirúrgico con sedación.

Si alguna de las respuestas es positiva, notifíquelo también y le serán indicados los pasos a seguir, su procedimiento debe ser reprogramado y debe contactar vía telefónica inmediatamente a los servicios de salud.

Nombre Padre o tutor:

Nombre Odontólogo Tratante:

$\begin{array}{ll}\text { Firma: } & \text { DNI o CC: } \\ \text { Firma: } & \text { DNI o CC: } \\ \text { Lugar: } & \text { Fecha: }\end{array}$

Firma: $\quad$ DNI o CC:

Lugar: $\quad$ Fecha: 


\section{Anexo 2}

\section{ALP ASOCIACIÓN LATINOAMERICANA DE ODONTOPEDIATRÍA}

LISTA DE COMPROBACIÓN PARA ACUDIR A LA CONSULTA DE

ODONTOPEDIATRÍA BAJO SEDACIÓN DURANTE LA PANDEMIA COVID-19

\begin{tabular}{|c|c|c|}
\hline \multicolumn{3}{|l|}{ ANTES DE SALIR DE CASA } \\
\hline Realiza teleconsulta /por teléfono - redes sociales / teleodontología & SI & NO \\
\hline Cumple el ayuno indicado por el Odontopediatra o el Anestesiólogo & $\square \mathrm{sI}$ & $\square \mathrm{NO}$ \\
\hline $\begin{array}{l}\text { Cumple com la toma de medicamentos indicada por el Odontopediatra o el Anestesiólogo } \\
\text { de ser el caso }\end{array}$ & $\square \mathrm{SI}$ & $\square \mathrm{NO}$ \\
\hline Prepara al paciente de forma positiva antes de la consulta (cuentos, videos, ambientación) & $\square \mathrm{sI}$ & $\square \mathrm{NO}$ \\
\hline $\begin{array}{l}\text { Mide la temperatura corporal (debe ser menor a } 37.5^{\circ} \mathrm{C} \text { ) } \\
\text { Si es mayor suspenda la cita y consulte a su médico }\end{array}$ & $\square \mathrm{sI}$ & $\square \mathrm{NO}$ \\
\hline Usa ropa cómoda & $\square \mathrm{sI}$ & $\square \mathrm{NO}$ \\
\hline $\begin{array}{l}\text { Lleva solo lo indispensable, incluyendo bolígrafo personal y bolsitas plásticas para colocar } \\
\text { mascarilla, teléfono u otros objetos }\end{array}$ & $\square$ SI & $\square \mathrm{NO}$ \\
\hline Prepara tu forma de pago: $\quad \square \square$ efectivo 洏 $\square$ crédito $\quad$ 领 $\square$ débito $\square$ & ransfere & ncia \\
\hline Realiza higiene oral de tu hijo & $\square \mathrm{sI}$ & $\mathrm{NO}$ \\
\hline Usan mascarilla durante el traslado al consultorio (paciente y acompañante) & $\square$ SI & $\mathrm{NO}$ \\
\hline $\begin{array}{l}\text { Se trasladan directo a la consulta, preferiblemente de forma particular, siguiendo las } \\
\text { normas de cada país. }\end{array}$ & $\square \mathrm{sI}$ & $\square \mathrm{NO}$ \\
\hline \multicolumn{3}{|l|}{ AL LLEGAR AL CONSULTORIO } \\
\hline Mantienen la mascarilla colocada en todo momento & $\square$ SI & $\mathrm{NO}$ \\
\hline Puede haber limpieza de zapatos, tapete con hipoclorito o uso de polainas des & SI & $\mathrm{NO}$ \\
\hline Le realizan medición de temperatura corporal con escáner $\left(<\right.$ a $\left.37,5^{\circ} \mathrm{C}\right)$ & SI & $\mathrm{NO}$ \\
\hline Guarda el teléfono celular higienizado & SI & $\mathrm{NO}$ \\
\hline Si vinieron con guantes, los retiran y desechan & $\square$ SI & $\mathrm{NO}$ \\
\hline Realizan higiene de manos & $\square$ SI & $\mathrm{NO}$ \\
\hline Lava de la cara del paciente & SI & $\bar{\square} \mathrm{NO}$ \\
\hline Puede colocarse vestimenta especial al con bata, babero y gorro & $\square \mathrm{SI}$ & $\square \mathrm{NO}$ \\
\hline \multicolumn{3}{|l|}{ DURANTE LA CONSULTA } \\
\hline Acompañante espera fuera del box dental & $\square$ SI & $\square \mathrm{NO}$ \\
\hline Realiza enjuague del paciente con solución desinfectante antes de comenzar el tratamiento & SI & $\mathrm{NO}$ \\
\hline El paciente mantiene colaboración apropiada para la realización del tratamiento & SI & $\mathrm{NO}$ \\
\hline Al finalizar la consulta, realiza higiene de manos y cara del paciente & $\square$ SI & $\mathrm{NO}$ \\
\hline Coloca la mascarilla en paciente y acompañante para salida del consultorio & $\square$ SI & $\mathrm{NO}$ \\
\hline \multicolumn{3}{|l|}{ AL LLEGAR A CASA } \\
\hline Dejan zapatos en la entrada del hogar & SI & $\mathrm{NO}$ \\
\hline Retiran mascarillas & SI & $\mathrm{NO}$ \\
\hline Realizan higiene de manos y cara & $\square$ SI & $\mathrm{NO}$ \\
\hline Idealmente realizan baño con lavado de cabello y cambio de ropa & $\square \mathrm{SI}$ & $\square \mathrm{NO}$ \\
\hline $\begin{array}{l}\text { Cumplen las indicaciones del Odontopediatra y del Anestesiólogo (recomendaciones y } \\
\text { prescripciones, tiempos de alimentacio'n) }\end{array}$ & $\square$ & 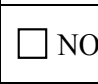 \\
\hline Mantienen hábitos apropiados de higiene bucal & $\square$ SI & $\square \mathrm{NO}$ \\
\hline
\end{tabular}

\section{¡TRABAJAMOS PARA QUE LOS NIÑOS SONRÍAN SANOS Y FELICES!}

¡RECUERDA MANTENER UNA ALIMENTACIÓN BALANCEADA Y

CUMPLE CON TODAS LAS MEDIDAS DE HIGIENE BUCAL APROPIADAS!

LA PREVENCIÓN ES DE ESPECIAL IMPORTANCIA 


\section{Anexo 3}

\section{ALQP ASOCIACIÓN LATINOAMERICANA DE ODONTOPEDIATRÍA}

Cod. 608-60

Asociación Latinoamericana de Odontopediatría. Lineamiento técnico de atención para procedimientos con sedacion durante la etapa de confinamiento y posterior declarados por la pandemia por el COVID19. Rev Latinoam Odontop. 2020; 10 (2).

ANEXO 3. Listas de chequeo para la atención de los pacientes en el consultorio odontológico. ${ }^{26}$

Lista de chequeo 1: Formación del personal asistencial y confirmación de los elementos de protección personal (EPP).

\begin{tabular}{|l|c|c|}
\hline $\begin{array}{l}\text { Lista de comprobación } \\
\text { Formación del personal y comprobación de EPP }\end{array}$ & \multicolumn{2}{|c|}{ Respuesta } \\
\hline Formación & SI & NO \\
\hline $\begin{array}{l}\text { Se ha realizado un curso o actividad de actualización de los nuevos } \\
\text { protocolos a implementar en el consultorio? }\end{array}$ & SI & NO \\
\hline Se ha realizado un simulacro previo a la reapertura? & SI & NO \\
\hline Comprobación de disponibilidad de EPP & SI & NO \\
\hline $\begin{array}{l}\text { Se ha comprobado existencia suficiente de mascarillas FFP2 o N95 y } \\
\text { mascarillas quirúrgicas? }\end{array}$ & SI & NO \\
\hline Se ha comprobado existencia suficiente de guantes? & SI & NO \\
\hline $\begin{array}{l}\text { Se ha comprobado existencia suficiente de gorros, polainas y batas } \\
\text { desechables de manga larga? }\end{array}$ & \multicolumn{2}{|c|}{} \\
\hline Se ha verificado existencia de protección ocular o pantalla facial? & \\
\hline EPP: elementos de protección personal &
\end{tabular}




\section{ALQP ASOCIACIÓN LATINOAMERICANA DE ODONTOPEDIATRÍA}

Cod. $608-60$

Lista de chequeo 2. Colocación y retirada de los elementos de protección personal (EPP).

\begin{tabular}{|l|c|c|}
\hline \multicolumn{2}{|l|}{ Lista de chequeo para el manejo de los EPP } \\
\hline Colocación de los EPP & Respuesta \\
\hline Se ha colocado los cubre calzados? & SI & NO \\
\hline Se ha lavado las manos con agua y jabon por mínimo 20 segundos? & SI & NO \\
\hline Se ha colocado la bata de manga larga? & SI & NO \\
\hline Se ha colocado el gorro y recogido el cabello? & SI & NO \\
\hline Se ha colocado la mascarilla N95 o FFP2 correctamente? & SI & NO \\
\hline Ha comprobado el ajuste correcto de la mascarilla? & SI & NO \\
\hline Se ha colocado la protección ocular o pantalla facial? & SI & NO \\
\hline $\begin{array}{l}\text { Se ha colocado doble par de guantes que cubran los puños de la bata } \\
\text { desechable? }\end{array}$ & \multicolumn{2}{|l|}{} \\
\hline Retirada de los EPP & SI & NO \\
\hline Se retiro el primer par de guantes? & SI & NO \\
\hline Se hizo desinfección del segundo par de guantes con gel alcoholado? & SI & NO \\
\hline Se retiro la bata desechable de atrás hacia delante, sin tocar la ropa de trabajo? & SI & NO \\
\hline Se hizo desinfección nuevamente de los guantes con gel alcoholado? & SI & NO \\
\hline $\begin{array}{l}\text { Se retiró la protección ocular o pantalla facial y lo ha desinfectado con } \\
\text { desinfectante en spray? }\end{array}$ & \multicolumn{2}{|c|}{} \\
\hline Se ha retirado la mascarilla y el gorro sin tocar ninguna parte del rostro? & SI & NO \\
\hline Ha desechado el material en la caneca con bolsa roja? & SI & NO \\
\hline $\begin{array}{l}\text { Se ha retirado el segundo par de guantes y se ha vuelto a lavar y desinfectar } \\
\text { las manos? }\end{array}$ & SI & NO \\
\hline
\end{tabular}




\section{ALQP ASOCIACIÓN LATINOAMERICANA DE ODONTOPEDIATRÍA}

Cod. $608-60$

Lista de chequeo 3. Adaptación de los espacios comunes y sala de espera del consultorio. Adaptación de los espacios comunes

\begin{tabular}{|l|c|c|}
\hline Recepción de pacientes & \multicolumn{2}{|c|}{ Respuesta } \\
\hline $\begin{array}{l}\text { Ha adaptado la recepción con el material sobre el escritorio mínimo } \\
\text { necesario? }\end{array}$ & SI & NO \\
\hline $\begin{array}{l}\text { Ha adaptado la recepción con barreras y ha señalizado el espacio de seguridad } \\
\text { de mínimo 1 metro hasta el mostrador? }\end{array}$ & SI & NO \\
\hline Hay gel alcoholado disponible en la recepción? & SI & NO \\
\hline
\end{tabular}

\section{Sala de espera}

\begin{tabular}{|l|c|c|}
\hline Ha retirado libros, revistas, folletos y decoración de la sala de espera? & SI & NO
\end{tabular}

Ha retirado el control del televisor y aire acondicionado?

Están las sillas dispuestas en la sala de espera con espacio de seguridad de 2 metros entre una y otra?

\begin{tabular}{|l|l|l|}
\hline Ha retirado el mobiliario tapizado o dificil de limpiar y desinfectar? & SI & NO
\end{tabular}

Ha retirado toda decoración innecesaria para facilitar la limpieza y desinfección?

\section{Baño}

En el baño, ha colocado jabón líquido con dispensador y papel secante?

En caso de disponer de secador de mano, lo ha retirado o desconectado?

Ha señalizado con cartel la técnica de lavado de manos y la prohibición de lavarse los dientes en ese espacio?

\section{Zonas comunes}

Ha aireado todos los espacios al inicio de la jornada laboral?

Ha comprobado que el aire acondicionado esta apagado y desconectado? 


\title{
ALQP ASOCIACIÓN LATINOAMERICANA DE ODONTOPEDIATRÍA
}

\author{
Cod. 608-60
}

Lista de Chequeo 4. Limpieza y desinfección de los espacios comunes.

\section{Limpieza y desinfección}

\begin{tabular}{|l|c|c|}
\hline Limpieza y desinfección de las zonas comunes & \multicolumn{2}{|c|}{ Respuesta } \\
\hline $\begin{array}{l}\text { Ha limpiado y desinfectado los suelos de todos los espacios comunes con las } \\
\text { soluciones adecuadas? }\end{array}$ & SI & NO \\
\hline Ha utilizado mopa en vez de aspirador o escoba? & SI & NO \\
\hline $\begin{array}{l}\text { Ha limpiado y desinfectado las manijas de las puertas y ventanas, } \\
\text { interruptores, pasamanos y apoya brazos? }\end{array}$ & SI & NO \\
\hline Ha limpiado y desinfectado el área de recepción, incluyendo las mámparas? & SI & NO \\
\hline Ha limpiado y desinfectado la mesa de trabajo, los teclados y las pantallas? & SI & NO \\
\hline Ha limpiado y desinfectado el teléfono y los intercomunicadores? & SI & NO \\
\hline Ha procedido a una limpieza y desinfección del baño, incluyendo el suelo? & SI & NO \\
\hline
\end{tabular}




\section{ALQP ASOCIACIÓN LATINOAMERICANA DE ODONTOPEDIATRÍA}

Cod. 608-60

Lista de Chequeo 5. Encuesta telefónica al paciente e instrucciones antes de asistir a la consulta.

\begin{tabular}{|l|c|c|}
\hline \multicolumn{2}{|l|}{ Triaje telefónico e instrucciones previas } & Respuesta \\
\hline Consulta telefónica & SI & NO \\
\hline Le ha preguntado si presenta o ha presentado fiebre en los últimos 14 días? & NO \\
\hline $\begin{array}{l}\text { Le ha preguntado si presenta tos o cualquier otro síntoma respiratorio en los } \\
\text { úlimos 14 días? }\end{array}$ & SI & NO \\
\hline $\begin{array}{l}\text { Le ha preguntado si presenta diarrea o síntomas digestivos en los últimos 14 } \\
\text { días? }\end{array}$ & SI & NO \\
\hline $\begin{array}{l}\text { Le ha preguntado si presenta cansancio o malestar general en los últimos 14 } \\
\text { días? }\end{array}$ & SI \\
\hline $\begin{array}{l}\text { Le ha preguntado si presenta perdida del olfato o del gusto en los últimos 14 } \\
\text { días? }\end{array}$ & SI & NO \\
\hline $\begin{array}{l}\text { Le ha preguntado si ha estado en contacto o conviviendo con alguien sospecho } \\
\text { o confirmado de COVID-19? }\end{array}$ & SI & NO \\
\hline $\begin{array}{l}\text { Le ha preguntado si ha tenido COVID-19 y en caso afirmativo, si sigue aislado } \\
\text { en cuarentena? }\end{array}$ & SI & NO \\
\hline $\begin{array}{l}\text { Instrucciones previa en caso de agendar la cita en el consultorio } \\
\text { Debe acudir sólo el paciente, pero en el caso de los menores de edad, debe ir } \\
\text { acompañado sólo de un familiar. }\end{array}$ & SI & NO \\
\hline $\begin{array}{l}\text { No asistir a consulta con accesorios como pulseras, anillos, pendientes o } \\
\text { collares }\end{array}$ & SI & NO \\
\hline Llegar puntual y no antes para evitar una espera innecesaria & SI & NO \\
\hline Al llegar debe realizar un correcto lavado de manos y aplicar gel alcoholado & SI & NO \\
\hline $\begin{array}{l}\text { Mantener la distancia social de mínimo 2 metros, si llega a encontrar otro } \\
\text { paciente en el consultorio }\end{array}$ & SI & NO \\
\hline $\begin{array}{l}\text { Hacer el pago de la consulta preferiblemente con tarjeta o medios digitales } \\
\text { para evitar manipular dinero en efectivo }\end{array}$ & SI & NO \\
\hline
\end{tabular}




\section{ALQP ASOCIACIÓN LATINOAMERICANA DE ODONTOPEDIATRÍA}

Cod. 608-60

Lista de chequeo 6. Recepción del paciente, paso al área clínica en el consultorio e instrucciones posteriores al procedimiento odontológico.

\begin{tabular}{|l|c|c|}
\hline Recepción del paciente, circulación en el área clínica e instrucciones postoperatorias \\
\hline Recepción del Paciente & \multicolumn{2}{|c|}{ Respuesta } \\
\hline Le ha dado el gel alcoholado para aplicarse en las manos? & SI & NO \\
\hline Mantiene la distancia de seguridad mínima de 1 metro con el personal? & SI & NO \\
\hline $\begin{array}{l}\text { Ha confirmado que el paciente no tiene accesorios y que deje en un lugar } \\
\text { seguro fuera del área clínica sus objetos personales? }\end{array}$ & SI & NO \\
\hline Paso al área clínica & \multicolumn{2}{|c|}{} \\
\hline $\begin{array}{l}\text { El paciente tiene colocadas las polainas o cubrezapatos antes de entrar al áerea } \\
\text { clínica? }\end{array}$ & SI & NO \\
\hline Le ha colocado el babero o delantal impermeable al paciente? & SI & NO \\
\hline $\begin{array}{l}\text { Le ha pedido que haga un enjuague bucal con peróxido de hidrógeno al 1\% o } \\
\text { povidona iodadada al 0,2\% (comprobar alergia al yodo). Debe mantener la } \\
\text { solución en la boca por al menos } 30 \text { segundos? }\end{array}$ & SI & NO \\
\hline Le ha colocado la protección ocular al paciente? & SI & NO \\
\hline $\begin{array}{l}\text { Ha comprobado que todos los dispositivos y equipos que van a entrar en } \\
\text { contacto con el paciente estan debidamente protegidos y en su funda? }\end{array}$ & SI & NO \\
\hline
\end{tabular}




\section{ALQP ASOCIACIÓN LATINOAMERICANA DE ODONTOPEDIATRÍA}

Cod. 608-60

Lista de chequeo 7. Aspectos de limpieza y desinfección: entre pacientes y al final de la jornada laboral.

\begin{tabular}{|c|c|c|}
\hline \multicolumn{3}{|l|}{ Limpieza y desinfección } \\
\hline Entre Pacientes & \multicolumn{2}{|c|}{ Respuesta } \\
\hline $\begin{array}{l}\text { Ha procedido a retirar todo el material contaminado (babero, paños, gasas, } \\
\text { boquilla de aspirador, película plástica, envolturas)? }\end{array}$ & SI & NO \\
\hline $\begin{array}{l}\text { Ha llevado al área de desinfección y esterilización el material e instrumental } \\
\text { contaminado (después de retirarse el primer guante externo)? }\end{array}$ & SI & NO \\
\hline $\begin{array}{l}\text { Ha depositado todo el material desechable en el contenedor de tapa dura en el } \\
\text { área de desinfección? }\end{array}$ & SI & NO \\
\hline Ha ventilado el área clínica cerrando la puerta (entre 5-10 minutos)? & SI & NO \\
\hline $\begin{array}{l}\text { Ha procedido a una minuciosa limpieza y desinfección de superficies, sillón } \\
\text { de odontología, escupidera, lámpara y bandeja de piezas de mano? Es } \\
\text { obligatorio utilizar EPP para esta tarea (guantes, gafas y tapabocas) }\end{array}$ & SI & NO \\
\hline $\begin{array}{l}\text { Ha dejado actuar el producto desinfectante al menos } 2 \text { minutos en las } \\
\text { superficies limpiadas? }\end{array}$ & SI & NO \\
\hline $\begin{array}{l}\text { Ha vuelto a preparar el espacio clínico debidamente, antes de pasar a otro } \\
\text { paciente (envoltura plástica, paños nuevos, fundas desechables para las piezas } \\
\text { de manos e instrumental empacado estéril y listo)? }\end{array}$ & SI & NO \\
\hline \multicolumn{3}{|l|}{ Laboratorio } \\
\hline $\begin{array}{l}\text { En caso de impresiones o prótesis: ¿las ha sometido al proceso adecuado de } \\
\text { limpieza y desinfección antes de enviarlas al laboratorio? }\end{array}$ & SI & NO \\
\hline \multicolumn{3}{|l|}{ Al final de la jornada laboral } \\
\hline $\begin{array}{l}\text { Ha procedido a una limpieza y desinfección de todas las superficies de trabajo } \\
\text { del área de desinfección/esterilización, autoclave, termoselladora y } \\
\text { contenedor? }\end{array}$ & SI & NO \\
\hline $\begin{array}{l}\text { Ha procedido a una minuciosa limpieza y desinfección de todas las superficies } \\
\text { de trabajo? }\end{array}$ & SI & NO \\
\hline $\begin{array}{l}\text { Ha procedido a una limpieza y desinfección del sillón de odontología, lámpara } \\
\text { y bandeja móvil? }\end{array}$ & SI & NO \\
\hline $\begin{array}{l}\text { Ha procedido a una limpieza y desinfección de la zona de escupidera? Dejar } \\
\text { actuar el desinfectante por al menos } 2 \text { minutos y activar el agua de la } \\
\text { escupidera para enjuagar. }\end{array}$ & SI & NO \\
\hline $\begin{array}{l}\text { Ha procedido a una minuciosa limpieza y desinfección del sistema de } \\
\text { aspiración del equipo incluyendo la parte interna del circuito? }\end{array}$ & SI & NO \\
\hline $\begin{array}{l}\text { Ha procedido a una limpieza y desin } \\
\text { interruptores y suelo del espacio clínico de }\end{array}$ & SI & $\mathrm{NO}$ \\
\hline
\end{tabular}

